\title{
A Single-Phase Three-Level Flying-Capacitor PFC Rectifier without Electrolytic Capacitors
}

\author{
Wenlong $\mathrm{Qi}^{1}$, Student Member, IEEE, Sinan $\mathrm{Li}^{1}$, Member, IEEE, Siew-Chong Tan ${ }^{1}$, Senior Member, \\ IEEE, and Shu-Yuen (Ron) Hui ${ }^{1,2}$, Fellow, IEEE, \\ 1 Department of Electrical and Electronic Engineering, The University of Hong Kong, Hong Kong, SAR \\ 2 Department of Electrical and Electronic Engineering, Imperial College London, London, U. K.
}

\begin{abstract}
A component-minimized and low-voltage-stress single-phase PFC rectifier without electrolytic capacitor is proposed in this paper. Component minimization is achieved by embedding an active pulsating-power-buffering (PPB) function within each switching period, such that typical add-on power electronic circuits for PPB is no longer needed. Additionally, with a three-level flying-capacitor configuration, the voltage stresses of switching devices can be reduced more than $50 \%$ as compared to existing solutions that are based on embedded PPB. The relationship between the inductance requirement and the patterns of the modulation carriers, and how it can be utilized to minimize the magnetics of the rectifier, is also discussed. A $110 \mathrm{~W}$ hardware prototype is designed and tested to demonstrate the feasibilities of the proposed rectifier. An input power factor of over 0.97 , peak efficiency of $95.1 \%$, and output voltage ripple of less than $4.3 \%$, across a wide load range have been experimentally obtained.
\end{abstract}

Index Terms-PFC rectifier, active power decoupling, three-level flying capacitor, automatic power decoupling.

\section{INTRODUCTION}

There is a growing demand for high power density, high conversion efficiency, and high reliability $\left(\mathrm{H}^{3}\right)$ single-phase $\mathrm{PFC}$ rectifiers in support of emerging technologies and applications. For example, the service lifetime of an LED driver is expected to match that of the state-of-the-art LED technologies (i.e., > 10 years) [1], [2], while the driver itself should fit inside a light bulb, which requires a high power density design of the driver [3]-[6]. A second example is that according to Quick Charge 4+ specifications, the envisaged power rating of a next-generation mobile phone charger is 4 times higher than that of conventional chargers. A substantial increase in the power density of the chargers is expected if the chargers' sizing is unchanged [7], [8].

\footnotetext{
Manuscript received May 13, 2018; revised August 05, 2018; accepted September 17, 2018. This work is supported by the Hong Kong Research Grant Council under GRF Project 17205817. The authors are with the Department of Electrical and Electronic Engineering, the University of Hong Kong, Hong Kong (email: wlqi@eee.hku.hk; snli@eee.hku.hk; sctan@eee.hku.hk; ronhui@eee.hku.hk).
}

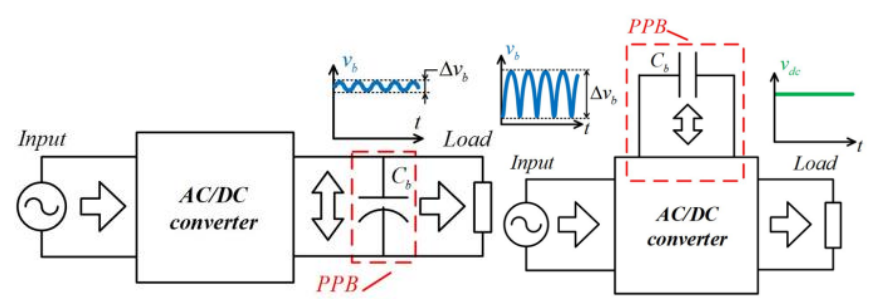

(a)

(b)

Fig. 1. (a) Power conversion architecture of conventional single-phase power converter with passive PPB and (b) three-port architecture with active PPB.

Single-phase PFC rectifiers inherently require a substantial energy storage capacity to buffer the double-line frequency power imbalance between the ac line and the dc load [9]-[14]. One effective approach to increase the power density of a PFC rectifier is to minimize the size of the system's energy storage requirement. Fig. 1(a) and (b), respectively, depict the power conversion architecture of a conventional single-phase PFC rectifier with passive pulsating-power-buffering (PPB) and a recently proposed three-port architecture with active PPB. As opposed to the conventional configuration where an energy storage capacitance $C_{b}$ is directly attached to the dc-link, the capacitance $C_{b}$ of the configuration in Fig. 1(b) is decoupled from the dc-link and its voltage has the freedom to fluctuate with a larger amplitude whilst retaining a constant dc-link voltage. Here $E_{P P B}=C_{b} \bar{V}_{c} \Delta v_{c}$, where $E_{P P B}$ is the PPB energy and is a constant irrespective of the size of $C_{b}, \Delta v_{c}$ is the peak-to-peak amplitude of the voltage ripple of $C_{b}$, and $\bar{V}_{c}$ is the average voltage of $C_{b}$. Therefore, $C_{b}$ can be drastically reduced by enlarging $\Delta v_{c}$. The power density of the rectifier is increased with a smaller $C_{b}$. It also enables non-electrolytic capacitors with prolonged lifetime and low ESR, e.g. film capacitors or laminated ceramic capacitors, to be used for PPB. This leads to high-reliability and high-efficiency system design of the rectifier.

Various types of single-phase PFC rectifiers with active PPB have been recently proposed. One possible type is based on the direct cascade of a dc active filter to the output of a front-end PFC rectifier to perform active PPB [15], [16]. Despite the reduction of energy storage size, the need for extra power electronics to form the dc active filter contradicts the aim of system volume reduction. To simplify the circuit structure, a concept of switch integration has been proposed. In [17]-[21], the interesting idea of sharing the use of one phase leg of the 
front-end full-bridge PFC rectifier with that of a half-bridge dc active filter, leading to an integrated solution without additional active switches, is explored. To further reduce the number of active and passive components used, a new concept of PPB embedded switching is recently proposed [22]-[25]. In a typical two-level converter (e.g. buck converter), there are only two switching states within one switching cycle. With the PPB embedded switching, extra switching states are introduced within one switching cycle and are utilized to achieve active PPB function. This discards the need for dc active filter and thereby saving more active switches. To date, among all the reported active $\mathrm{PPB}$ rectifiers, the single-phase rectifiers employing PPB embedded switching achieves the minimum number of active and passive components used. However, despite their merits, these rectifiers suffer badly from high voltage stress. Active switches and diodes in most of the configurations reported must withstand a voltage up to $V_{a c}+V_{d c}$, where $V_{a c}$ is the peak line voltage and $V_{d c}$ is the output voltage. This leads to higher switching losses and the mandatory use of expensive high-voltage components.

In this paper, a low-voltage-stress single-phase $\mathrm{PFC}$ rectifier with a three-level flying-capacitor configuration and PPB embedded switching is proposed. The number of active switches and inductors remains minimum at two and one respectively, while the flying capacitor serves two purposes of clamping the voltage stresses of all power devices and operating as a PPB capacitor. The solution effectively overcomes the drawbacks of previous solutions. The operating principles, control method, as well as design considerations of the rectifier, are detailed in Section II to IV. Section IV also provides a discussion on the relationship between the inductance requirements versus different modulation methods, and an explanation on how this relationship can be utilized to minimize the magnetics of the rectifier. Section $\mathrm{V}$ presents the experimental results under various steady-state and dynamic operating conditions. Section VI give a conclusion to this paper.

\section{Single-Phase ThreE-LeVEl Flying-CAPACITOR PFC RECTIFIER WITH PPB EMBEDDED SWITCHING}

\section{A. Circuit Configuration}

Fig. 2(a) and (b) show respectively the circuit configurations of a conventional buck-boost PFC rectifier and the proposed three-level PFC rectifier with PPB embedded switching. Compared to the former, the proposed converter is augmented with one additional set of active switch $S_{B}$, diode $D_{B}$ and capacitor $C_{b}$. The converter can be regarded as a buck-boost version of the conventional three-level flying-capacitor converter based on a buck converter's configuration [26]. An extra charging and discharging state of the flying capacitor $C_{b}$ is created by the extra components, as will be detailed in Section II-B. Consequently, active PPB function can be embedded within each switching cycle, leading to substantially reduced requirement for $C_{b}$ as compared to that of the rectifier configuration given in Fig. 1(a). Importantly, the proposed rectifier enjoys low voltage stresses for its switching devices due to the voltage clamping characteristic of the three-level configuration. Moreover, inductor $L$ can be significantly reduced via appropriate modulation methods, as will be explained in Section IV.
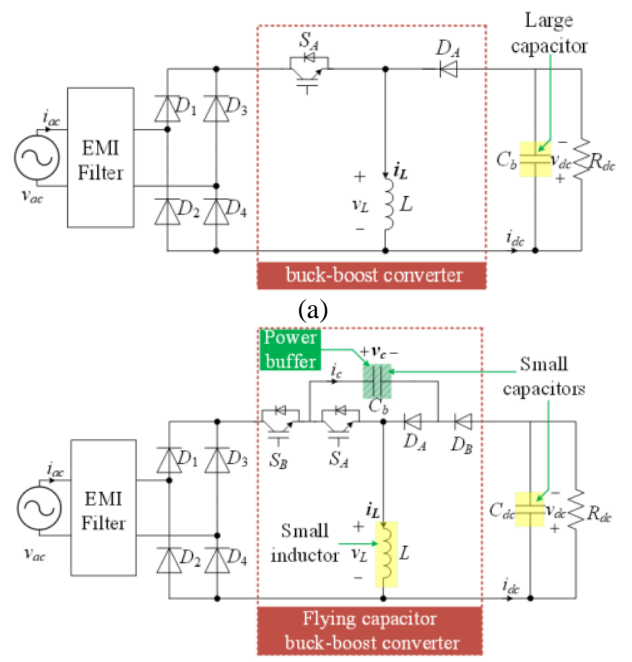

(b)

Fig. 2. Circuit diagrams of (a) conventional buck-boost PFC rectifier and (b) the proposed three-level flying-capacitor PFC rectifier based on PPB embedded switching.

\section{B. Operating Principles}

Assuming the continuous-conduction-mode (CCM) of operation, the rectifier has four switching states as depicted in Fig. 3. Here, the electromagnetic interference (EMI) filter is neglected and the ac line voltage $v_{a c}$ and the front-end diode bridge are presented as a rectified voltage source $\left|v_{a c}\right|$.
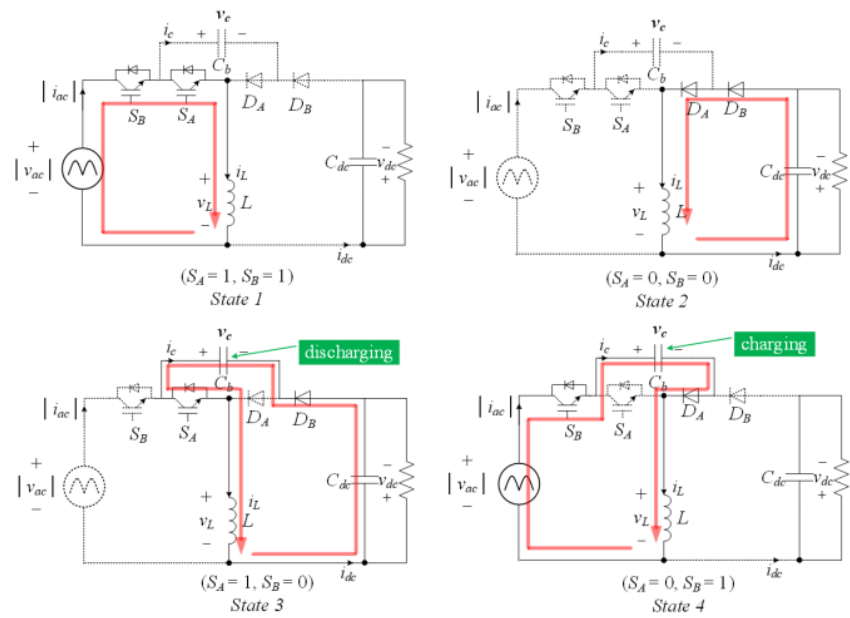

Fig. 3. Equivalent circuits of the proposed rectifier during State 1-State 4.

In State 1 and State 2, both the active switches $S_{A}$ and $S_{B}$ are concurrently turned on and off, respectively, and inductor $L$ is charged by the input voltage $\left|v_{a c}\right|$ and discharged to the load $\left(C_{d c}\right.$ and $R_{d c}$ ), respectively. These two switching states are identical to that of a conventional buck-boost converter. Here, the capacitor $C_{b}$ is in the idle mode. In State 3 and State $4, C_{b}$ is part of the power flow path. Specifically, $C_{b}$ is discharged with an inductor current $i_{L}$ in State 3 and charged by $i_{L}$ in State 4 . By controlling the duration of State 3 and State 4, active PPB 
utilizing $C_{b}$ can be achieved. The switching patterns of the four switching states, the corresponding charging/discharging states of $C_{b}$, and the inductor voltage $v_{L}$ are summarized in Table I.

Table I. Summary of Switching States.

\begin{tabular}{|c|c|c|c|c|}
\hline \hline $\begin{array}{c}\text { Operating } \\
\text { State }\end{array}$ & $\boldsymbol{S}_{\boldsymbol{A}}$ & $\boldsymbol{S}_{\boldsymbol{B}}$ & $\boldsymbol{C}_{\boldsymbol{b}}$ & $\boldsymbol{v}_{\boldsymbol{L}}$ \\
\hline State 1 & 1 & 1 & Idle & $\left|v_{a c}\right|$ \\
\hline State 2 & 0 & 0 & Idle & $-v_{d c}$ \\
\hline State 3 & 1 & 0 & Discharge & $v_{c}-v_{d c}$ \\
\hline State 4 & 0 & 1 & Charge & $\left|v_{a c}\right|-v_{c}$ \\
\hline \hline
\end{tabular}

\section{Steady-State Circuit Analysis}

Assuming a unity power factor and pure sinusoidal waveforms for the ac line voltage $v_{a c}$ and current $i_{a c}$, i.e.,

$$
\left\{\begin{array}{l}
v_{a c}=V_{a c} \sin \omega t \\
i_{a c}=I_{a c} \sin \omega t
\end{array}\right.
$$

where $V_{a c}$ and $I_{a c}$ are the amplitudes of $v_{a c}$ and $i_{a c}$, and $\omega$ is the line frequency, the instantaneous input power at the ac line $p_{a c}$ can be expressed as

$$
p_{a c}=v_{a c} i_{a c}=\underbrace{\frac{V_{a c} I_{a c}}{2}}_{P_{d c}} \underbrace{-\frac{V_{a c} I_{a c}}{2} \cos (2 \omega t)}_{p_{r}} .
$$

Equation (2) indicates that $p_{a c}$ consists of a constant dc power $P_{d c}$ and a double-line-frequency pulsating power $p_{r}$. To output a stable dc power, $p_{r}$ must be fully buffered by $C_{b}$. Assuming that the power in $L$ is purely reactive and all power losses are neglected, the voltage and current of $C_{b}$ can thus be calculated as [17], [27]

$$
\begin{gathered}
v_{c}=\sqrt{\bar{V}_{c}^{2}-\frac{P_{d c}}{\omega C_{b}} \sin (2 \omega t)}, \\
i_{c}=-\frac{P_{d c} \cos (2 \omega t)}{\sqrt{\bar{V}_{c}^{2}-\frac{P_{d c}}{\omega C_{b}} \sin (2 \omega t)}},
\end{gathered}
$$

where $\bar{V}_{c}$ is the average voltage of $v_{c}$ and is a design variable.

By denoting the durations of State 1-State 4 respectively as $d_{1} T_{s}, d_{2} T_{s}, d_{3} T_{s}$ and $d_{4} T_{s}$, where $T_{s}$ is the switching period, then $d_{1}-d_{4}$ must comply with the equation

$$
d_{1}+d_{2}+d_{3}+d_{4}=1 \text {. }
$$

Based on Table I, the duty cycles of the switches $S_{A}$ and $S_{B}$ are related to $d_{1}-d_{4}$ as

$$
\begin{aligned}
& d_{A}=d_{1}+d_{3}, \\
& d_{B}=d_{1}+d_{4} .
\end{aligned}
$$

Meanwhile, with reference to Fig.3, input current $i_{a c}$, output current $i_{d c}$ and capacitor current $i_{c}$ over $T_{s}$ can be respectively calculated as

$$
\begin{gathered}
\left\langle\mid i_{a c}\right\rangle_{T s}=\left(d_{1}+d_{4}\right)\left\langle i_{L}\right\rangle_{T s}=d_{B}\left\langle i_{L}\right\rangle_{T s}, \\
\left\langle i_{d c}\right\rangle_{T s}=\left(d_{2}+d_{3}\right)\left\langle i_{L}\right\rangle_{T s}=\left(1-d_{B}\right)\left\langle i_{L}\right\rangle_{T s},
\end{gathered}
$$

$$
\left\langle i_{c}\right\rangle_{T s}=\left(d_{4}-d_{3}\right)\left\langle i_{L}\right\rangle_{T s}=\left(d_{B}-d_{A}\right)\left\langle i_{L}\right\rangle_{T s}{ }^{\prime}
$$

where $\left\langle i_{L}\right\rangle_{T S}$ is the averaged inductor current over $T_{s}$. It is evident from (10) that when $d_{3}>d_{4}$ (or $d_{A}>d_{B}$ ), $\left\langle i_{c}\right\rangle_{T s}$ is negative and $C_{b}$ is discharged, and vice versa. This is consistent with the description given in Fig. 3. Summation of (8) and (9) leads to the steady-state expression of $\left\langle i_{L}\right\rangle_{T s}$ as

$$
\left\langle i_{L}\right\rangle_{T s}=\left\langle\mid i_{a c}\right\rangle_{T s}+\left\langle i_{d c}\right\rangle_{T s} .
$$

Hence, $\left\langle i_{L}\right\rangle_{T s}$ is varying at the double-line frequency with a dc offset. Solution of (8)-(11) yields the steady-state equations of $d_{A}$ and $d_{B}$ as

$$
\left\{\begin{array}{c}
d_{A}=\frac{\left\langle i_{a c} \mid\right\rangle_{T s}-\left\langle i_{c}\right\rangle_{T s}}{\left\langle i_{L}\right\rangle_{T s}}=\frac{\left\langle\left|i_{a c}\right|\right\rangle_{T s}-\left\langle i_{c}\right\rangle_{T s}}{\left\langle\left|i_{a c}\right|\right\rangle_{T s}+\left\langle i_{d c}\right\rangle_{T s}} \\
d_{B}=\frac{\left\langle\mid i_{a c}\right\rangle_{T s}}{\left\langle i_{L}\right\rangle_{T s}}=\frac{\left\langle\left|i_{a c}\right|\right\rangle_{T s}}{\left\langle\left|i_{a c}\right|\right\rangle_{T s}+\left\langle i_{d c}\right\rangle_{T s}}
\end{array} .\right.
$$

To ensure the circuit operation, $d_{A}$ and $d_{B}$ in (12) must be within the range of $0-100 \%$. Therefore, the first operating constraint of the rectifier is

$$
-\left\langle i_{d c}\right\rangle_{T s} \leq\left\langle i_{c}\right\rangle_{T s} \leq\left\langle\left|i_{a c}\right|\right\rangle_{T s} .
$$

According to Fig.3, a second operating constraint of the rectifier is

$$
\left|v_{a c}\right|+V_{d c} \geq v_{c} .
$$

Equation (14) ensures that $D_{B}$ is reverse biased and turned OFF in State 1 and State 4.

Solution of (13) indicates that the output voltage $V_{d c}$ has a lower boundary of

$$
V_{d c} \geq \frac{V_{a c}}{2},
$$

which can be explained using (35) in Section IV.

The voltage conversion characteristics of the rectifier can be obtained as follows. By averaging (2) over a line period $T_{\text {line }}$ and utilizing (8) and (9), one yields

$$
\left\langle v_{d c}\right\rangle=\frac{\left\langle d_{B}\left|v_{a c}\right|\left\langle i_{L}\right\rangle_{T s}\right\rangle_{T_{\text {line }}}}{\left\langle\left(1-d_{B}\right)\left\langle i_{L}\right\rangle_{T s}\right\rangle_{T_{\text {line }}}} .
$$

Equation (16) shows the steady-state voltage conversion characteristics of the proposed rectifier. It resembles that of the conventional buck-boost converter, except that there are extra averaging operator and inductor current term in the denominator and numerator, respectively. Based on (15) and (16), the rectifier can theoretically give any positive output voltage higher than $V_{a c} / 2$ provided that the operating constraints of (13) and (14) are satisfied.

\section{Gate signal generation}

The gate signal generation method is not unique. According to (8)-(10), duty ratios $d_{1}, d_{2}$ and $d_{4}$ can be expressed in terms of $d_{3}$ as 


$$
\left\{\begin{array}{c}
d_{1}=\frac{\left\langle\left|i_{a c}\right|\right\rangle_{T s}-\left\langle i_{c}\right\rangle_{T s}}{\left\langle i_{L}\right\rangle_{T s}}-d_{3}=\frac{\left\langle\left|i_{a c}\right|\right\rangle_{T s}-\left\langle i_{c}\right\rangle_{T s}}{\left\langle\left|i_{a c}\right|\right\rangle_{T s}+\left\langle i_{d c}\right\rangle_{T s}}-d_{3} \\
d_{2}=\frac{\left\langle i_{d c}\right\rangle_{T s}}{\left\langle i_{L}\right\rangle_{T s}}-d_{3}=\frac{\left\langle i_{d c}\right\rangle_{T s}}{\left\langle\left|i_{a c}\right|\right\rangle_{T s}+\left\langle i_{d c}\right\rangle_{T s}}-d_{3} \\
d_{4}=\frac{\left\langle i_{c}\right\rangle_{T s}}{\left\langle i_{L}\right\rangle_{T s}}+d_{3}=\frac{\left\langle i_{c}\right\rangle_{T s}}{\left\langle\left|i_{a c}\right|\right\rangle_{T s}+\left\langle i_{d c}\right\rangle_{T s}}+d_{3}
\end{array} .\right.
$$

Equation (17) suggests that there is freedom in choosing $d_{3}$, which leads to different $d_{1}, d_{2}, d_{4}$ and thus different inductor current ripples. The patterns of the signal carriers for modulating $d_{A}$ and $d_{B}$ have a direct impact on $d_{3}$. Fig. 4 shows one possible modulation strategy where $d_{A}$ and $d_{B}$ are modulated using two $180^{\circ}$ phase-shifted triangular carriers, Carrier_a and Carrier_b, respectively. Phase-shifted modulation is commonly adopted for controlling multilevel converters to boost the effective switching frequency, resulting in a minimized volume of the magnetics [14], [26], [28].

As shown in Fig. 4, the active switching states are State 1, State 3 and State 4 when $d_{A}+d_{B} \geq 1$, while they change to State 2, State 3 and State 4 when $d_{A}+d_{B}<1$. In both scenarios, the voltage across the inductor is switched between three voltage levels. Mathematically, this means

$$
\left\{\begin{array}{ll}
d_{1}+d_{3}+d_{4}=1 & \left(d_{A}+d_{B} \geq 1\right) \\
d_{2}+d_{3}+d_{4}=1 & \left(d_{A}+d_{B}<1\right)
\end{array} .\right.
$$

Solution of (17) and (18) leads to the steady-state duty ratios of $d_{1}-d_{4}$ as shown in (19) and (20).

$$
\begin{aligned}
& \left\{\begin{array}{l}
d_{1}=d_{A}+d_{B}-1=\frac{\left\langle i_{a c} \mid\right\rangle_{T s}-\left\langle i_{c}\right\rangle_{T s}-\left\langle i_{d c}\right\rangle_{T s}}{\left\langle i_{a c} \mid\right\rangle_{T s}+\left\langle i_{d c}\right\rangle_{T s}} \\
d_{2}=0 \\
d_{3}=d_{A}-d_{1}=\frac{\left\langle i_{d c}\right\rangle_{T s}}{\left\langle\left|i_{a c}\right|\right\rangle_{T s}+\left\langle i_{d c}\right\rangle_{T s}} \quad\left(d_{A}+d_{B} \geq 1\right) \\
d_{4}=d_{B}-d_{1}=\frac{\left\langle i_{c}\right\rangle_{T s}+\left\langle i_{d c}\right\rangle_{T s}}{\left\langle\left|i_{a c}\right|\right\rangle_{T s}+\left\langle i_{d c}\right\rangle_{T s}} \\
d_{2}=1-d_{A}-d_{B}=\frac{\left\langle i_{d c}\right\rangle_{T s}-\left\langle\left|i_{a c}\right|\right\rangle_{T s}+\left\langle i_{c}\right\rangle_{T s}}{\left\langle\mid i_{a c}\right\rangle_{T s}+\left\langle i_{d c}\right\rangle_{T s}} \\
d_{3}=d_{A}=\frac{\left\langle\left|i_{a c}\right|\right\rangle_{T s}-\left\langle i_{c}\right\rangle_{T s}}{\left\langle\left|i_{a c}\right|\right\rangle_{T s}+\left\langle i_{d c}\right\rangle_{T s}} \\
d_{4}=d_{B}=\frac{\left\langle\left|i_{a c}\right|\right\rangle_{T s}}{\left\langle\left|i_{a c}\right|\right\rangle_{T s}+\left\langle i_{d c}\right\rangle_{T s}}
\end{array}\right.
\end{aligned}
$$

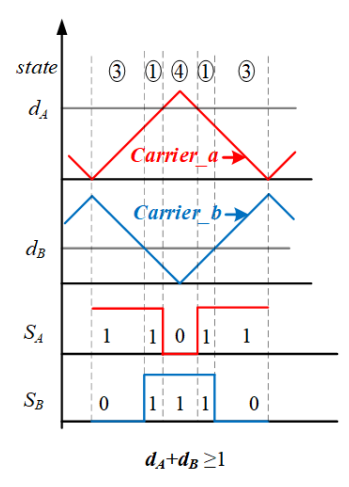

(a)

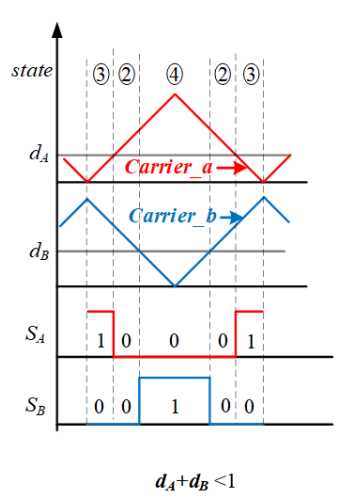

(b)
Fig. 4. Gate signal patterns for $S_{A}$ and $S_{B}$ generated by two $180^{\circ}$ - shifted triangular carriers when (a) $d_{A}+d_{B} \geq 1$ and (b) $d_{A}+d_{B}<1$.
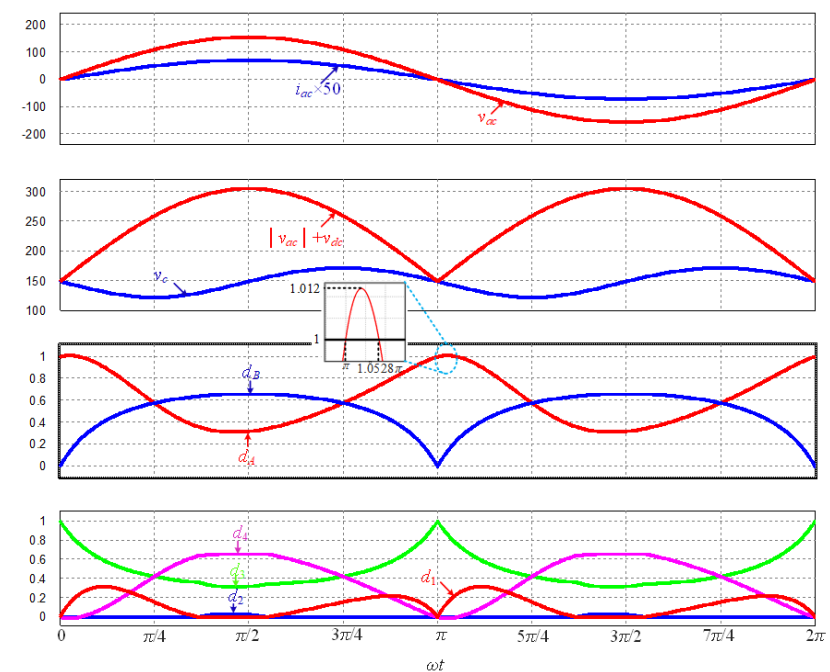

Fig. 5. Calculated $d_{1}-d_{4}, d_{A}, d_{B}$ and the key system operating waveforms.

Fig. 5 depicts the calculated waveforms of $\left|v_{a c}\right|+V_{d c}, v_{c}$, $d_{1}-d_{4}, d_{A}$ and $d_{B}$ during a line period for a $110 \mathrm{~W}$ rectification system, where the average voltage of $v_{c}$ over a line period is chosen as $\bar{V}_{c}=V_{d c}\left(110 \mathrm{~V}_{\mathrm{rms}}\right.$ ac input, and $150 \mathrm{~V}$ dc output $)$. The detailed specifications used in the calculation can be found in Section IV and V. It is shown that operating constraint (14) is always satisfied and $d_{B}$ falls within the range of $0-100 \%$. However, the calculated $d_{A}$ marginally exceeds the limit of $100 \%$ at around the zero-crossing instant of the line voltage for a very short interval, and will be bounded at $100 \%$ in a practical design. According to (12)), $d_{A}$ exceeding $100 \%$ indicates that $\left.-\left\langle i_{d c}\right\rangle_{T s}\right\rangle\left\langle i_{c}\right\rangle_{T s}$ during this short interval and thus the constraints in (13) are violated. In practice, however, this is generally not a problem because (i) $\left\langle i_{a c}\right\rangle_{T s}$ and $\left\langle i_{d c}\right\rangle_{T s}$ can still be precisely regulated according to (8) and (9) through the control of $d_{B}$, and (ii) the period of $d_{A}$ exceeding $100 \%$ can be designed very short by properly selecting $C_{b}$, as will be demonstrated in Section IV.

\section{Enhanced Automatic Power Decoupling Control}

Theoretically, an open-loop control based on (12) can be employed to achieve the desired circuit operation. However, a practical converter inevitably possesses power losses, 
component tolerances and nonlinearities, which must be properly compensated through a closed-loop control. As discussed in [29], [30], a three-port PFC rectifier in Fig. 1(b) is essentially a highly coupled and highly nonlinear system. In this paper, the nonlinear control method known as Enhanced Automatic Power Decoupling (E-APD) control that has been proposed in [29], [30], is adopted. The controller can numerically transform the original system into two fully decoupled and linear subsystems to achieve enhanced robustness and stability via a simple control structure.

According to Fig.3, the state-space-averaged equations of the rectifier can be obtained as

$$
\left\{\begin{array}{l}
L \frac{d i_{L}}{d t}=d_{B}\left|v_{a c}\right|-\left(1-d_{B}\right) v_{d c}-\left(d_{A}-d_{B}\right) v_{c} \\
C_{d c} \frac{d v_{d c}}{d t}=-\frac{v_{d c}}{R_{d c}}+d_{A} i_{L} \\
C_{b} \frac{d v_{c}}{d t}=\left(d_{B}-d_{A}\right) i_{L}
\end{array} .\right.
$$

The three differential equations in (21) describe the dynamics at the ac port (i.e., $i_{L}$ ), dc port (i.e., $v_{d c}$ ) and the ripple port (i.e., $v_{c}$ ), respectively. (21) also indicates that the system is coupled (between the system dynamics and the two control inputs (i.e., $d_{A}$ and $d_{B}$ ) ) and nonlinear (due to the multiplying operation of the control inputs and system states). The E-APD control strategy requires the ac and dc port dynamics to be the control outputs. Therefore, two new control inputs, $u_{A}$ and $u_{B}$, are introduced such that

$$
\left\{\begin{array}{l}
L \frac{d i_{L}}{d t}=u_{B} \\
C_{d c} \frac{d v_{d c}}{d t}=-\frac{v_{d c}}{R_{d c}}+u_{A}
\end{array},\right.
$$

where $u_{A}$ and $u_{B}$ are, respectively,

$$
\left\{\begin{array}{l}
u_{A}=d_{A} i_{L} \\
u_{B}=d_{B}\left|v_{a c}\right|-\left(1-d_{B}\right) v_{d c}-\left(d_{A}-d_{B}\right) v_{c}
\end{array} .\right.
$$
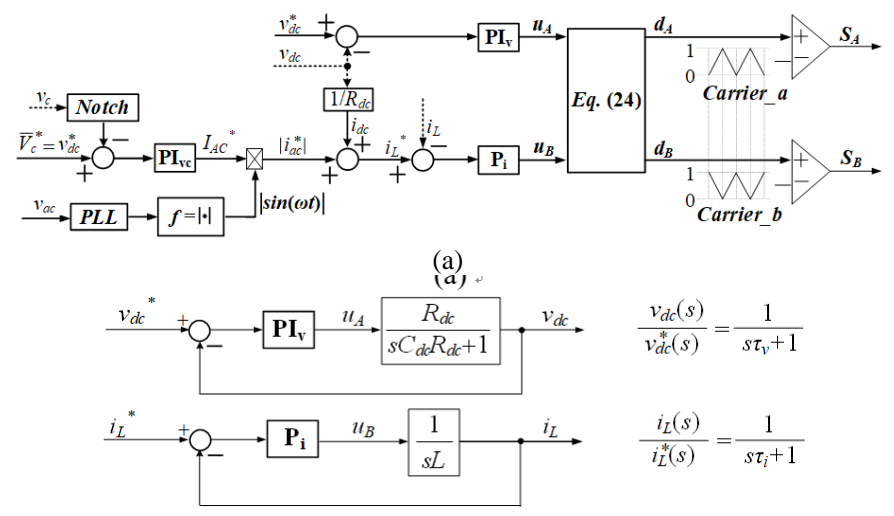

(b)

Fig. 6. (a) Overall control diagrams of the employed enhanced automatic-power-decoupling control and (b) its equivalent closed-loop diagram.

Equation (22) describes two decoupled and first-order linear subsystems, where $i_{L}$ and $v_{d c}$ can be individually controlled by $u_{A}$ and $u_{B}$. Conventional linear controllers can then be easily designed to achieve the desired steady-state and dynamic performance. With the E-APD control, the dynamics at the ripple-port, i.e., $v_{c}$, is indirectly controlled and no dedicated PPB control is needed. This is because any power imbalance between the ac-port and dc-port power (which are determined by $i_{L}$ and $v_{d c}$ ) shall be automatically transferred to the ripple port according to the energy conservation principle.

Fig. 6 (a) shows the complete control block diagram of the proposed PFC rectifier. Here $u_{A}$ and $u_{B}$ are firstly obtained from a proportional-Integral (PI) and a proportional $(\mathrm{P})$ compensator, i.e., $\mathrm{PI}_{\mathrm{v}}$ and $\mathrm{P}_{\mathrm{i}}$, respectively, which are converted into $d_{A}$ and $d_{B}$ and then modulated for generating the gate driving signals. The feedback-linearization-decoupling law for converting the new control inputs (i.e., $u_{A}$ and $u_{B}$ ) back to the original control inputs (i.e., $d_{A}$ and $d_{B}$ ) can be derived by solving (23) as

$$
\left\{\begin{array}{l}
d_{A}=\frac{u_{A}}{i_{L}} \\
d_{B}=\frac{u_{B}+v_{d c}-d_{A} v_{c}}{\left|v_{a c}\right|+v_{d c}-v_{c}}
\end{array} .\right.
$$

The equivalent closed-loop diagram of Fig. 6(a) is depicted in Fig. 6(b) based on (22). By following the same design procedure as discussed in [29], the $\mathrm{PI}_{\mathrm{v}}$ and $\mathrm{P}_{\mathrm{i}}$ controller can be designed with the equation

$$
\left\{\begin{array}{l}
G_{\mathrm{PI} v}(s)=\frac{C_{b}}{\tau_{v}}+\frac{1}{\tau_{v} R_{d c} s} \\
G_{\mathrm{P} i}(s)=\frac{L}{\tau_{i}}
\end{array},\right.
$$

leading to first-order closed-loop responses of the $v_{d c}$ and $i_{L}$ loop (with a time constant of $\tau_{v}$ and $\tau_{i}$, respectively) [29]. In Fig. 6(a), the reference signal $i_{L}{ }^{*}$ is obtained by summing the rectified line current reference $\left|i_{a c}{ }^{*}\right|$ and the output current $i_{d c}$ according to (11), where $\left|i_{a c}^{*}\right|$ is obtained from an outer voltage loop regulating $\bar{V}_{c}$ at $\bar{V}_{c}^{*}$ and $i_{d c}$ is estimated from $v_{d c}$ for simplicity. Here, $\bar{V}_{c}^{*}=v_{d c}^{*}$ is selected to meet the operating constraint of (14) whilst maximizing the voltage fluctuation range of $v_{c}$. A notch filter with a stopping band at the double-line frequency is employed to extract $\bar{V}_{c}$.

\section{DESIGN CONSIDERATIONS}

\section{A. Active Switches and Diodes Design}

The voltages across the power devices of the proposed PFC rectifier during State 1-State 4 are shown in Table II, based on which their minimum voltage ratings are also calculated. Due to the flying capacitor configuration, the minimum voltage ratings of $S_{A}$ and $D_{A}$ (i.e., $V_{A}$ ) are equal to $V_{c \max }$ (i.e., the maximum voltage of $v_{c}$ ),

$$
V_{A}=V_{c \max }=\sqrt{V_{d c}^{2}+\frac{P_{d c}}{\omega C_{b}}}
$$


while the minimum voltage ratings for $S_{B}$ and $D_{B}$ (i.e., $V_{B}$ ) are equal to the maximum voltage of $v_{d c}+\left|v_{a c}\right|-v_{c}$,

$$
V_{B}=\max _{0 \leq t \leq T_{\text {Iine }}}\left\{V_{d c}+\left|V_{a c} \sin \omega t\right|-\sqrt{V_{d c}^{2}-\frac{P_{d c}}{\omega C_{b}} \sin (2 \omega t)}\right\} .
$$

Table II. Voltage stresses and minimum voltage ratings.

\begin{tabular}{|c|c|c|c|c|c|}
\hline \hline Operating State & $\boldsymbol{S}_{\boldsymbol{A}}$ & $\boldsymbol{D}_{\boldsymbol{A}}$ & $\boldsymbol{S}_{\boldsymbol{B}}$ & $\boldsymbol{D}_{\boldsymbol{B}}$ & $\boldsymbol{D}_{\mathbf{1}}-\boldsymbol{D}_{\mathbf{4}}$ \\
\hline State 1 & 0 & $v_{c}$ & 0 & $v_{d c}+\left|v_{a c}\right|-v_{c}$ & \\
\hline State 2 & $v_{c}$ & 0 & $v_{d c}+\left|v_{a c}\right|-v_{c}$ & 0 & \\
\hline State 3 & 0 & $v_{c}$ & $v_{d c}+\left|v_{a c}\right|-v_{c}$ & 0 & \\
\hline State 4 & $v_{c}$ & 0 & 0 & $v_{d c}+\left|v_{a c}\right|-v_{c}$ & \\
\hline $\begin{array}{c}\text { Minimum voltage } \\
\text { rating }\end{array}$ & $V_{A}$ & $V_{A}$ & $V_{B}$ & $V_{B}$ & $V_{a c}$ \\
\hline \hline
\end{tabular}

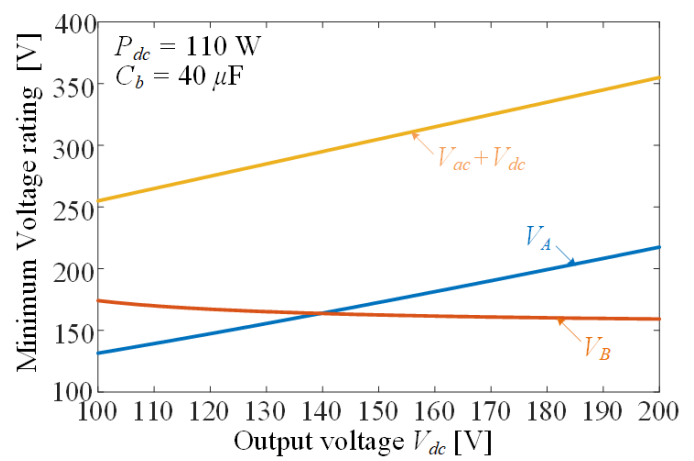

(a)

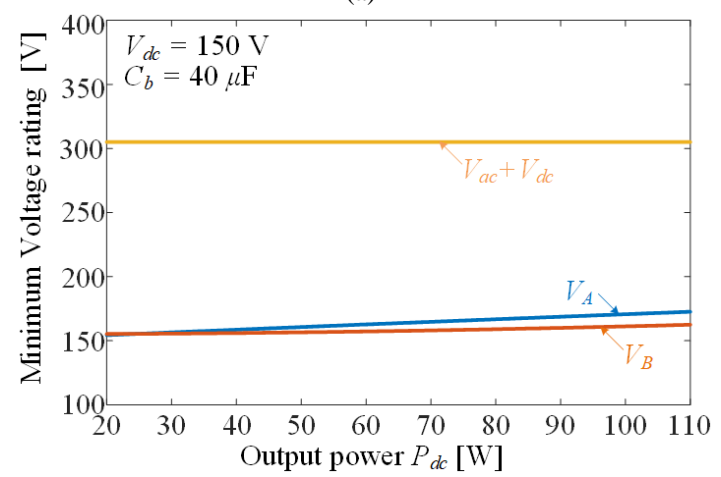

(b)

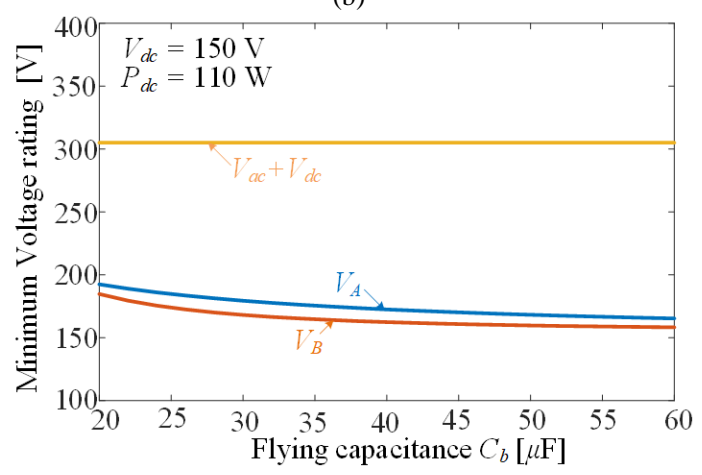

(c)

Fig. 7. The minimum voltage stresses versus (a) output voltage, (b) output power and (c) flying capacitance.

In Fig. 7, $V_{A}$ and $V_{B}$ are compared against $V_{a c}+V_{d c}$ with respect to different (i) output voltage, (ii) output power, and (iii) PPB capacitance. Based on Fig. 7, the following observations can be made:
(1) In Fig. 7(a), $V_{A}$ scales almost linearly with $V_{d c}$ while $V_{B}$ remains approximately constant at $V_{a c}$. The linearity of $V_{A}$ versus $V_{d c}$ is evident from (26), as $V_{A} \approx V_{d c}$ if $V_{d c}{ }^{2} \gg \frac{P_{d c}}{\omega C_{b}}$, while the quasi-constant characteristic of $V_{B}$ is mainly due to (27) that $V_{B}=\max _{0 \leq t \leq T_{\text {live }}}\left\{\left|v_{a c}\right|+\Delta v_{c}\right\} \approx \max _{0 \leq t \leq T_{\text {live }}}\left\{\left|v_{a c}\right|\right\}=V_{a c}$ provided that the voltage ripple $\Delta v_{c}$ is sufficiently small as compared to $V_{a c}$. The above observations indicate that operating the rectifier at a low $V_{d c}$ helps to reduce the voltage stress of $V_{A}$ and the switching loss of $S_{A}$. However, a low $V_{d c}$ leads to high conduction losses especially in the output diodes $D_{A}$ and $D_{B}$. If $V_{d c}$ can be chosen with flexibility, such as in front-end PFC applicaions, an optimal $V_{d c}$ might be selected close to $V_{a c}$ (i.e., here $V_{a c}=155 \mathrm{~V}$ ), in this situation, $V_{A} \approx V_{B} \approx V_{d c} \approx V_{a c}$. This not only ensures a low profile of the conduction loss but also enables power devices with similar voltage ratings to be selected;

(2) In Fig. 7(b), $V_{d c}$ is fixed at $150 \mathrm{~V}$. Both $V_{A}$ and $V_{B}$ increase almost linearly with $P_{d c}$ but at a very slow rate. This is because $V_{A} \approx V_{B} \approx V_{d c} \approx V_{a c}$ which are almost constant as mentioned above for Fig. 7(a). The slight deviation of $V_{A}$ and $V_{B}$ from $V_{d c}$ at different $P_{d c}$ is mainly due to the increased voltage ripple $\Delta v_{c}$ as $P_{d c}$ increases. Overall, $V_{A}$ and $V_{B}$ exhibit almost similar maximum voltage stresses within a wide load range when $V_{d c} \approx$ $V_{a c}$ is selected;

(3) In Fig. 7(c), both $V_{A}$ and $V_{B}$ are found decreasing with the increase of $C_{b}$ for a constant $V_{d c}$ and $P_{d c}$. Again, this is simply because a larger $C_{b}$ leads to a smaller $\Delta v_{c}$;

(4) The voltage stresses of $V_{A}$ and $V_{B}$ are approximately half of $V_{a c}+V_{d c}$ for a wide range of $P_{d c}$ and $C_{b}$ combinations when $V_{d c}$ $\approx V_{a c}$, as $V_{A} \approx V_{B} \approx V_{d c} \approx V_{a c}$.

\section{B. Flying Capacitor Design}

With the objective of power density improvement, $C_{b}$ should be minimized under the constraints of (13) and (14) whilst ensuring that the voltage ratings of all power devices are not exceeded.

Firstly, according to (3) and (4) and noticing $\bar{V}_{c}=V_{d c}, v_{c}$ and $i_{c}$ can be expressed as

$$
\begin{gathered}
v_{c}=\sqrt{V_{d c}^{2}-\frac{P_{d c}}{\omega C_{b}} \sin (2 \omega t)}, \\
i_{c}=-\frac{P_{d c} \cos (2 \omega t)}{\sqrt{V_{d c}^{2}-\frac{P_{d c}}{\omega C_{b}} \sin (2 \omega t)}} .
\end{gathered}
$$

In the meantime, it is assumed that the variation range of $d_{A}$ and $d_{B}$ are

$$
\left\{\begin{array}{l}
0 \leq d_{A} \leq 1+\varepsilon \\
0 \leq d_{B} \leq 1
\end{array}\right.
$$

where $\varepsilon>0$ is the incremental duty cycle exceeding $100 \%$, as explained in Section II, and is a design choice. A smaller $\varepsilon$ implies a shorter duration of the period when $d_{A}$ is clamped at 
$100 \%$. By combining (12), (14) and (30), one obtains the precise operating constraints of the rectifier as

$$
\left\{\begin{array}{c}
-(1+\varepsilon) i_{d c}-\varepsilon\left|i_{a c}\right| \leq i_{c} \leq\left|i_{a c}\right| \\
v_{c} \leq\left|v_{a c}\right|+v_{d c}
\end{array} .\right.
$$

Solution of (31) using (28) and (29) leads to the first design constraint of $C_{b}$ as:

$$
C_{b} \geq \max \left\{C_{b 1}, C_{b 2}, C_{b 3}\right\},
$$

where

$$
\begin{gathered}
C_{b 1}=\max _{\omega t \in(0,2 \pi]}\left(\frac{P_{d c} \sin (2 \omega t)}{-\omega V_{a c}\left(2 V_{d c}|\sin \omega t|+V_{a c} \sin ^{2} \omega t \mid\right)}\right), \\
\left.C_{b 2}=\max _{\omega t \in\left(0, \frac{\pi}{4}\right)}\right)\left(\frac{3 \pi}{4}, \frac{5 \pi}{4}\right)\left(\frac{7 \pi}{4}, 2 \pi\right) \\
C_{b 3}=\frac{P_{d c} \sin (2 \omega t) / \omega}{V_{d c}^{2}-\left(\frac{V_{d c} \cos (2 \omega t)}{(1+\varepsilon)+\frac{2 \varepsilon V_{d c}}{V_{a c}}|\sin \omega t|}\right)^{2}}, \\
\omega\left(V_{d c}{ }^{2}-\left(\frac{V_{a c}}{2}\right)^{2}\right)
\end{gathered}
$$

For $\varepsilon=2 \%, P_{d c}=110 \mathrm{~W}, V_{d c}=150 \mathrm{~V}$, and $V_{a c}=155 \mathrm{~V}$, it can be numerically determined that $C_{b 1}=12.55 \mu \mathrm{F}, C_{b 2}=12.97 \mu \mathrm{F}$, and $C_{b 3}=17.69 \mu \mathrm{F}$. Then according to (32), $C_{b} \geq 17.69 \mu \mathrm{F}$

Secondly, the design constraints of $C_{b}$ regarding the voltage ratings of all power devices can be resolved based on (26), (27) and Fig. 7(c), given $V_{A} \leqslant V_{A_{-} d}$ and $V_{B} \leq V_{B_{-} d}$. Fig. 7(c) shows that both $V_{A}$ and $V_{B}$ increase monotonically with the reduction of $C_{b}$. Therefore, the minimum $C_{b}$ complying with the voltage stresses requirement can be easily determined. For example, given $V_{A_{-} d}=V_{B_{-} d}=175 \mathrm{~V}$, Fig. 7(c) indicates that

$$
C_{b} \geq C_{b 4}
$$

where $C_{b 4}=36 \mu \mathrm{F}$ can be identified. The final selection of $C_{b}$ must satisfy both (32) and (36). Therefore, $C_{b}=40 \mu \mathrm{F}$ is selected in this design.

\section{Inductor Design}

The inductor $L$ should be designed such that (i) the rectifier operates in the CCM and (ii) the high-frequency inductor current ripple $\Delta i_{L}$ is less than a pre-specified value $\Delta i_{L_{-} \text {rated }}$.

The CCM operation requires that

$$
\Delta i_{L}<2 i_{L}
$$

According to (11), the minimum value of $i_{L}$ during $T_{\text {line }}$ is $I_{d c}$ when $i_{a c}=0$. As the maximum value of $\Delta i_{L}$ is $\Delta i_{L_{-} \text {rated }}$, a sufficient condition for ensuring CCM operation is

$$
\Delta i_{L_{-} \text {rated }}<2 I_{d c_{-} \text {min }}
$$

where $I_{d c_{-} \min }$ is the minimum load current.

To satisfy design criteria (ii), the peak-to-peak inductor current ripple $\Delta i_{L}$ needs to be resolved. The patterns of the carriers for modulating $d_{A}$ and $d_{B}$ have a major impact on $\Delta i_{L}$ and thereby leading to different inductance requirement. In this study, four typical carrier patterns are studied (depicted in Fig. 8), namely, a pair of triangular carriers which are in phase and $180^{\circ}$ phase-shifted (carrier pair $w$ and $x$, respectively), and a pair of sawtooth carriers which are in phase and out of phase (carrier pair $y$ and $z$, respectively). Here, carriers pair $x$ is employed as an illustrative example for calculating $\Delta i_{L}$.

The inductor current waveform within one switching cycle is depicted in Fig. 9. At instances $t_{1}-t_{6}, i_{L}$ reaches its peaks or valleys of $i_{L n}$, respectively, where $n \in\{1,2,3,4,5,6\}$, and

$$
i_{L(m+1)}=i_{L m}+\Delta i_{L m}, m \in\{1,2,3,4,5\},
$$

with $\Delta i_{L m}$ being the incremental inductor current during the interval from $t_{m}$ to $t_{m+1}$. According to the annotated switching states as shown in Fig. 9, $\Delta i_{L m}$ can be derived as

$$
\left\{\begin{array}{l}
\Delta i_{L 1}=\frac{\gamma_{1}}{L}=\frac{d_{3} T_{s}\left(v_{c}-v_{d c}\right)}{2 L} \\
\Delta i_{L 2}=\frac{\gamma_{2}}{L}= \begin{cases}\frac{d_{1} T_{s}\left|v_{a c}\right|}{2 L} & \left(d_{A}+d_{B} \geq 1\right) \\
-\frac{d_{2} T_{s} v_{d c}}{2 L} & \left(d_{A}+d_{B}<1\right)\end{cases} \\
\Delta i_{L 3}=\frac{\gamma_{3}}{L}=\frac{d_{4} T_{s}}{L}\left(\left|v_{a c}\right|-v_{c}\right) \\
\Delta i_{L 4}=\frac{\gamma_{4}}{L}= \begin{cases}\frac{d_{1} T_{s}\left|v_{a c}\right|}{2 L} & \left(d_{A}+d_{B} \geq 1\right) \\
-\frac{d_{2} T_{s} v_{d c}}{2 L} & \left(d_{A}+d_{B}<1\right)\end{cases} \\
\Delta i_{L 5}=\frac{\gamma_{5}}{L}=\frac{d_{3} T_{s}\left(v_{c}-v_{d c}\right)}{2 L}
\end{array} .\right.
$$

The peak-to-peak inductor current ripple $\Delta i_{L}$ during the kth switching period is therefore

$$
\Delta i_{L}[k]=\max \left\{i_{L 1}[k], \cdots i_{L 6}[k]\right\}-\min \left\{i_{L 1}[k], \cdots i_{L 6}[k]\right\},
$$

which is a function of $L$. The minimum inductance $L_{\min }$ can be obtained by equating the maximum $\Delta i_{L}$ over $T_{\text {line }}$ to $\Delta i_{L_{-} \text {rated }}$ with the aid of (1), (19), (20) and (28) and is resolved as

$$
L_{\text {min }}=\frac{1}{\Delta i_{L_{\text {r rated }}}} \max _{k \in\left[1, T_{\text {line }} / T_{s}\right]}\left(\begin{array}{l}
\max \left\{0, \sum_{1}^{i=1} \gamma_{i}[k], \cdots \sum_{1}^{i=5} \gamma_{i}[k]\right\}- \\
\min \left\{0, \sum_{1}^{i=1} \gamma_{i}[k], \cdots \sum_{1}^{i=5} \gamma_{i}[k]\right\}
\end{array}\right)
$$

Following a similar calculation procedure, $\Delta i_{L}$ for other carrier pairs in Fig. 8 can be obtained and their corresponding $L_{\min }$ can be determined. The minimum inductance requirement for the conventional buck-boost PFC rectifier in Fig. 2(a) is also calculated as

$$
L_{\min }^{\prime}=\max \left\{\frac{v_{d c}\left|v_{a c}\right| T_{s}}{\left(v_{d c}+\left|v_{a c}\right|\right) \Delta i_{L_{-} \text {rated }}}\right\},
$$

given the same ripple requirement and $\mathrm{CCM}$ operation.

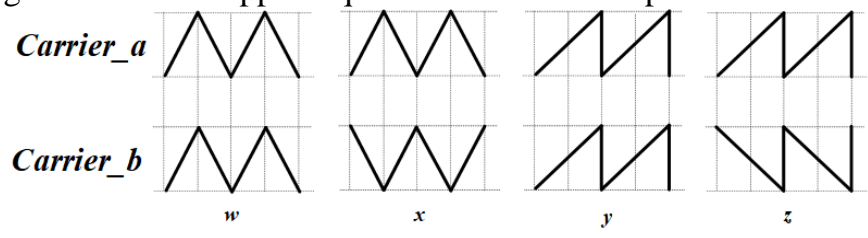


Fig. 8. Four patterns of tested carriers.

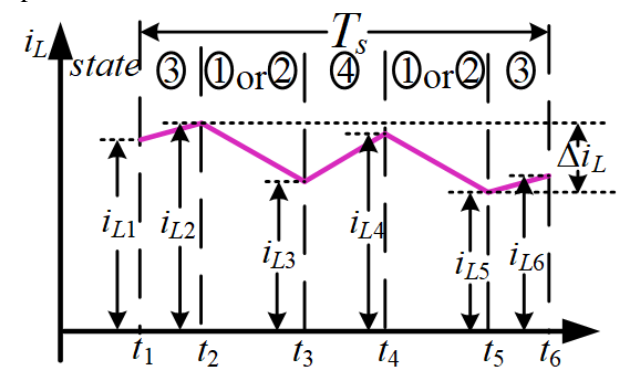

Fig. 9. Schematic diagram of the inductor current with carriers pair $x$ during one switching period.

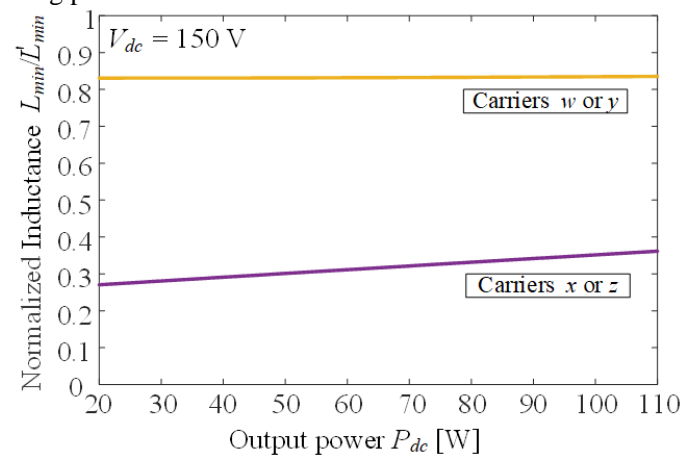

(a)

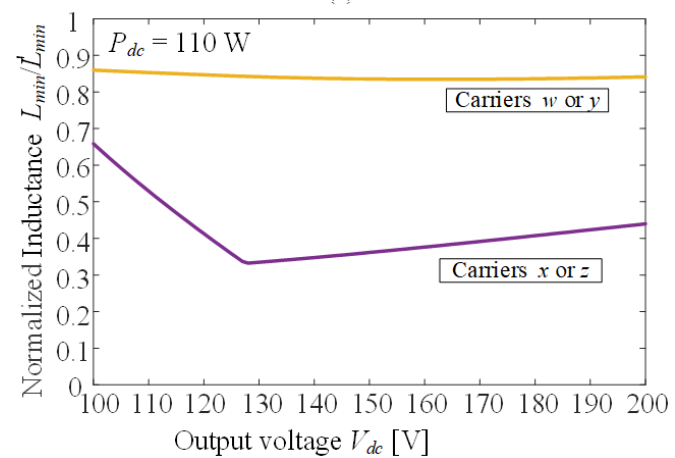

(b)

Fig. 10. The normalized minimum inductance requirement for the proposed PFC rectifier with four types of carrier pair versus (a) output power and (b) output voltage.

In Fig. 10(a) and (b), the normalized minimum inductance requirement ( $L_{\min } / L_{\min }^{\prime}$ ) for the proposed rectifier with four types of carrier pair are compared at different $P_{d c}$ and $V_{d c}$, respectively. Here, $\Delta i_{L_{-} \text {rated }}=0.6 \mathrm{~A}, C_{b}=40 \mu \mathrm{F}$, are selected in order to perform the calculation. With reference to these curves, the following observation can be made:

(1) In both Fig. 10(a) and (b), firstly, $L_{\min }$ for carrier pair $x$ is found identical to that of $z$ (both are out-of-phase carrier pair), while that for $w$ is identical to that for $y$ (both are in-phase carrier pair). Secondly, $L_{\min }$ for $x$ and $z$ is much smaller than that for $w$ and $y$ throughout the whole $P_{d c}$ and $V_{d c}$ range (e.g., at $V_{d c}=$ $128 \mathrm{~V}$, an inductance reduction of more than $60 \%$ can be obtained.) The results suggest that out-of-phase carriers are highly effective in minimizing the magnetics of the proposed rectifier. Thirdly, $L_{\min }$ for all types of carrier pair is smaller than $L_{\min }^{\prime}$. This is expected as the proposed rectifier employs a three-level structure while the conventional buck-boost PFC rectifier is a two-level switching converter;
(2) In Fig. 10(a), $L_{\min }$ for $w$ and $y$ is almost constant while that for $x$ and $z$ scales linearly with $P_{d c}$. Therefore, $L_{\min }$ should be designed at full load power;

(3) In Fig. 10(b), $L_{\min }$ for $w$ and $y$ increases with the output voltage, while that for $x$ and $z$ firstly decreases and then increases with $V_{d c}$. The curve suggests that for wide-output-voltage-range applications, $L_{\min }$ should be selected based on the maximum $V_{d c}$ when $w$ or $y$ is selected, while $L_{\text {min }}$ should be designed based on the minimum and the maximum $V_{d c}$ with $x$ or $z$.

Per above discussions, $L=2.5 \mathrm{mH}$ can be selected for a 100 V-200 V output, $110 \mathrm{~W}$ system modulated with carriers pair $x$ or $z$.

\section{Comparison with Prior-Art Buck-Boost-Derived PFC Rectifiers}

Compared with a boost-type PFC rectifier, the proposed buck-boost type rectifier provides two key advantages:

(i) due to its voltage step-down capability, a buck-boost type rectifier provides a cost-effective single-stage power conversion solution for applications that require low output voltage and no galvanic isolation, such as low-voltage LED driving. With a boost type rectifier, a secondary dc/dc stage for voltage step down is needed, increasing the overall cost and lowering the system's power density;

(ii) a buck-boost type rectifier can also be used as a front-end PFC for applications that require galvanic isolation (implemented in the secondary stage), such as personal computer adapters, etc. Compared with a boost-type front-end, a buck-boost type front-end can provide a lower dc-link voltage. Therefore, switches with lower voltage ratings can be utilized in the secondary stage. A lower voltage rating switch typically offers an improved figure-of-merit (FOM), leading to reduced switching and conduction losses.

Based on the above considerations, four buck-boost type circuit topologies are examined and compared. They are listed as follows:

1. Circuit-A: conventional buck-boost rectifier shown in Fig. 2(a);

2. Circuit-B: a buck-boost rectifier cascaded by a buck-type dc active filter shown in Fig. 11(a);

3. Circuit-C: a previously proposed PPB embedded switching PFC rectifier shown in Fig 11. (b) [21];

4. Circuit-D: the proposed three-level flying-capacitor PFC rectifier shown in Fig 2(b).

The comparison is conducted with respect to twelve key figure-of-merits (See Table III and IV), including the number of active switches and inductors used, size of buffering capacitance, level of voltage stresses of the semiconductor switches, size of the inductance required, estimated efficiency, and cost, etc. For efficiency comparison, component part number specified in Table IV is utilized to conduct the analysis. All the topologies are evaluated under the same conditions: $f_{s w}$ $=25 \mathrm{kHz}, P_{d c}=110 \mathrm{~W}, V_{d c}=150 \mathrm{~V}, V_{a c}=155 \mathrm{~V}$, and $\Delta i_{L_{-} \text {rated }}=$ $0.6 \mathrm{~A}$ for the inductor. The buffering capacitance of the 
conventional buck-boost PFC rectifier is designed for a $5 \%$ peak-to-peak dc voltage ripple, while that for the other three topologies are designed assuming $\Delta v_{c}=33 \%$ of $V_{d c}$.

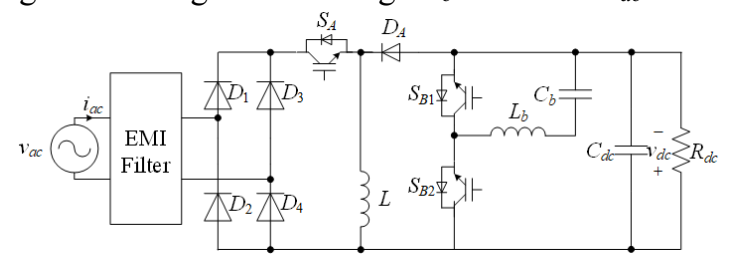

(a)

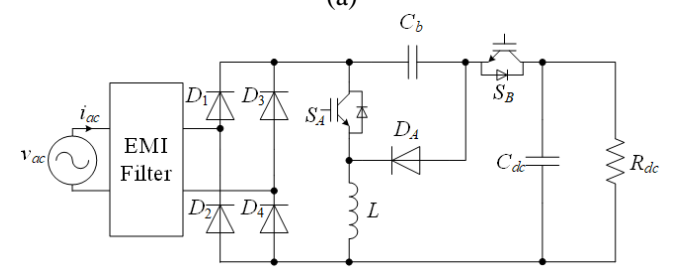

(b)

Fig. 11. (a) Buck-boost rectifier cascaded by a buck-type dc active filter, and (b) PPB embedded switching buck-boost PFC rectifier in [21].

Table III. Comparison of the Proposed Circuit with Prior-Art Buck-Boost PFC

\begin{tabular}{|c|c|c|c|c|}
\hline \multicolumn{5}{|c|}{ Rectifiers. } \\
\hline & Circuit-A & Circuit-B & Circuit-C & Circuit-D \\
\hline $\begin{array}{c}\text { Power Buffering } \\
\text { Method }\end{array}$ & Passive & Active & Active & Active \\
\hline$C_{b}(\mu \mathrm{F})$ & 259.5 & 46.7 & 20.1 & 40.0 \\
\hline $\begin{array}{c}\text { Peak Voltage of } \\
\text { Buffering } \\
\text { Capacitor }(\mathrm{V})\end{array}$ & 150 & 150 & 360 & 175 \\
\hline $\begin{array}{l}\text { Maximum Stored } \\
\text { Energy of } C_{b}(\mathrm{~J})\end{array}$ & 5.8 & 1.1 & 2.6 & 1.2 \\
\hline $\begin{array}{c}\text { Number of } \\
\text { Active Switches }\end{array}$ & 1 & 3 & 2 & 2 \\
\hline $\begin{array}{c}\text { Number of } \\
\text { Inductors }\end{array}$ & 1 & 2 & 1 & 1 \\
\hline $\begin{array}{l}\text { Voltage Stress of } \\
\text { Active Switches } \\
\text { (V) }\end{array}$ & $S_{A}: 305$ & $\begin{array}{l}S_{A}: 305 \\
S_{B 1}: 150 \\
S_{B 2}: 150\end{array}$ & $\begin{array}{l}S_{A}: 360 \\
S_{B}: 187\end{array}$ & $\begin{array}{l}S_{A}: 175 \\
S_{B}: 175\end{array}$ \\
\hline $\begin{array}{c}\text { Voltage Stress of } \\
\text { Diodes (V) }\end{array}$ & $D_{A}: 305$ & $D_{A}: 305$ & $D_{A}: 360$ & $\begin{array}{l}D_{A}: 175 \\
D_{B}: 175\end{array}$ \\
\hline$L(\mathrm{mH})$ & 5.1 & 5.1 & 5.1 & 1.8 \\
\hline$L_{b}(\mathrm{mH})$ & 0 & 1.4 & 0 & 0 \\
\hline $\begin{array}{c}\text { Estimated } \\
\text { efficiency }(\%)\end{array}$ & 95.5 & 94 & 93.9 & 95.1 \\
\hline
\end{tabular}

From Table III, the following observations can be made:

(i) Solutions based on active PPB can significantly reduce the energy storage (> 55\% reduction) as compared to the passive solution. As the stored energy needed is directly proportional to the volume of the capacitor (assuming a constant dielectric), the results indicate a volume reduction of more than $55 \%$ in the PPB capacitor. Table III also indicates that almost minimum energy storage is achieved via using Circuit B and Circuit D;

(ii) Among all the active PPB solutions, rectifier based on PPB embedded switching concept (Circuit C and Circuit D) achieves the minimum number of active switches and inductors used;

(iii) The voltage stress of the buck-boost switch $S_{A}$ in Circuit $A$ and Circuit B are independent of the PPB capacitance and are fixed at $V_{a c}+V_{d c}=305 \mathrm{~V}$, while those for Circuit C and Circuit D are PPB capacitance dependent. With an enlarged ripple $\Delta v_{c}$ due to a smaller $C_{b}$, the voltage stress of $S_{A}$ in Circuit $\mathrm{C}$ is increased by $19.6 \%$. In contrast, Circuit $\mathrm{D}$ has the lowest voltage stress among all the four topologies (i.e., $42.6 \%$ reduction compared to Circuit $\mathrm{A}$ and Circuit $\mathrm{B}$, and $51.3 \%$ compared to Circuit $\mathrm{C}$ ). In addition, the voltage stress of the diodes (except for the diode bridge) in Circuit D are also the lowest among the solutions;

(iv) The main inductances $L$ for Circuit A to $\mathrm{C}$ are identical, given the same inductor current ripple requirement. In contrast, Circuit D achieves $64.7 \%$ reduction in the main inductance by employing an out-of-phase carrier pair for modulation.

(v) Circuit-D achieves the highest efficiency among all active-PPB-based solutions and achieves comparable efficiency compared with Circuit-A. Despite that Circuit-D uses more active switches and diodes than Circuit-A, the voltage rating of Circuit-D is lower than that of Circuit-A, enabling switches with lower conduction and switching loss to be selected; additionally, the inductance requirement of the circuit- $\mathrm{D}$ is smaller than that of circuit-A. Therefore, the inductor copper losses is reduced in circuit-D.

\section{EXPERIMENTAL VERIFICATION}

\begin{tabular}{|c|c|c|c|}
\hline Parameters & Values & Parameters & Values \\
\hline $\begin{array}{c}\text { Input ac RMS } \\
\text { voltage }\end{array}$ & $110 \mathrm{~V}$ & Line frequency & $60 \mathrm{~Hz}$ \\
\hline $\begin{array}{l}\text { Output dc } \\
\text { voltage } v_{d c}\end{array}$ & $100-200 \mathrm{~V}$ & $\begin{array}{l}\text { Switching } \\
\text { frequency }\end{array}$ & $25 \mathrm{kHz}$ \\
\hline $\begin{array}{l}\text { Output capacitor } \\
C_{d c}\end{array}$ & $10 \mu \mathrm{F}$ & $\begin{array}{c}\text { Flying capacitor } \\
C_{b}\end{array}$ & $40 \mu \mathrm{F}$ \\
\hline Inductor $L$ & $2.5 \mathrm{mH}$ & Load resistor $R_{d c}$ & $350 \Omega$ \\
\hline $\begin{array}{c}D_{1}-D_{4,} D_{A} \text { and } \\
D_{B}\end{array}$ & UF5404-E3/54 & $S_{A}$ and $S_{B}$ & SIHP25N40 \\
\hline Input EMI filter & $1 \mathrm{mH}, 1 \mu \mathrm{F}$ & $\tau_{v}$ and $\tau_{i}$ & $0.8 \mathrm{~ms} \& 0.08 \mathrm{~ms}$ \\
\hline
\end{tabular}

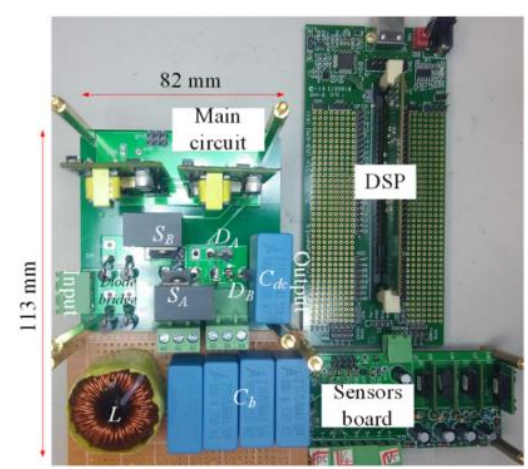

Fig. 12. Photograph of the experimental setup.

A proof-of-concept $110 \mathrm{~W}$ prototype with the component specifications given in Table IV is constructed and tested as shown in Fig. 12. An off-the-shelf $40 \mu \mathrm{F} / 250 \mathrm{~V}$ film capacitor is chosen for $C_{b}$ by trading off between minimizing the PPB capacitance and voltage stresses of the power components. An inductor of $2.5 \mathrm{mH}$ is selected for $L$ to ensure a maximum inductor current ripple of $0.6 \mathrm{~A}$ and $\mathrm{CCM}$ operation according to Fig. 10. The front-end EMI filter is designed to have a cut-off frequency of $5 \mathrm{kHz}$ to smoothen the input current profile (see Table IV). The E-APD controller is implemented using a 
low-cost DSP (TMS320F28069). It should be noted that the E-PAD controller is employed only to demonstrate the fast $V_{d c}$ regulation capability of the rectifier. In applications such as LED lighting and fast charger, $V_{d c}$ is fixed and/or has slow dynamics, and thus there is no need to perform fast $V_{d c}$ regulation. Standard linear controllers (e.g. PI, Proportional-Resonant (PR)) which are low cost are also alternative control solutions. The design of linear controllers for regulating an active-PPB-based rectifier is explicitly reported in [18].

The steady-state waveforms of the proposed PFC rectifier are shown in Fig. 13 (a)-(c), with an output voltage of $100 \mathrm{~V}, 150$ $\mathrm{V}$, and $200 \mathrm{~V}$ respectively In all the three scenarios, unity power factor is achieved, and the output voltage is well regulated at the respective references with low-frequency voltage ripples of 7.5 $\mathrm{V}, 8.2 \mathrm{~V}$ and $8.7 \mathrm{~V}$, respectively. The low-frequency voltage ripples are mainly caused by components' tolerance, sensing errors, quantization errors of the ADCs, and unmodeled system dynamics, and can be further reduced by (i) improving the sensing accuracy by choosing high-precision sensors and optimizing the sensing circuit design; (ii) minimizing the computational and zero-order-hold delay by optimizing the code (e.g. using assembly language instead of $\mathrm{C}$ language) and/or performing delay compensation; (iii) increasing the loop gain and/or the control bandwidth by optimally designing the controller (e.g. incorporating a proportional-resonant (PR) or repetitive controller which has infinite gain at a specific frequency). Meanwhile, the voltage across the PPB capacitor $C_{b}$ is pulsating significantly at a double-line frequency, indicating that $C_{b}$ is buffering the imbalanced power between the input and output. The peak-to-peak voltage variation of $v_{c}$ are $23 \mathrm{~V}, 36 \mathrm{~V}$, and $45 \mathrm{~V}$, respectively, which match well to the design specifications according to (28). These waveforms also confirm that the proposed rectifier has both voltage step down and step up capabilities and that a wide output voltage range is attainable.

The voltage waveforms of all switching devices are captured and compared to $v_{a c}$ and $v_{c}$ at different output voltage levels, as illustrated in Fig. 14. It can be seen that voltage stresses for $S_{A}$ and $D_{A}$ are clamped by $v_{c}$ which scales proportionally with $V_{d c}$. Therefore, $V_{A}$ is minimum (i.e., $112 \mathrm{~V}$ ) among the three tested scenarios when $V_{d c}$ is minimum (i.e., $100 \mathrm{~V}$ ), and vice versa. On the other hand, the voltage stress $V_{B}$ is almost constant in all three scenarios. The results confirm the previous analysis that $V_{B} \approx V_{a c}$ for a wide load and power range. The voltage stresses at the optimal output voltage are annotated in Fig. 14 (b), from which it is evident that all power devices, including the diodes in

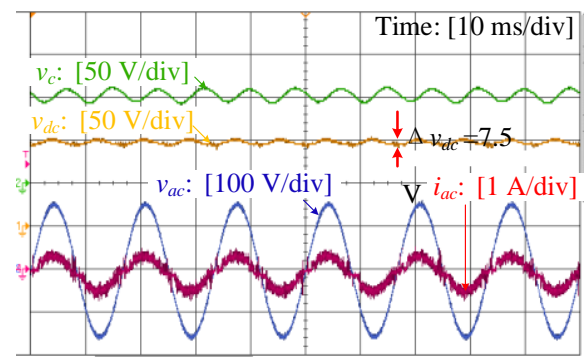

(a)

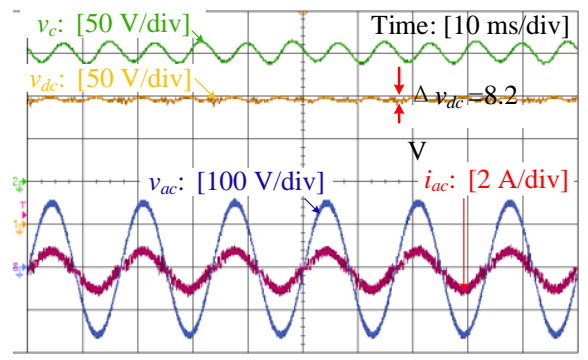

(b)

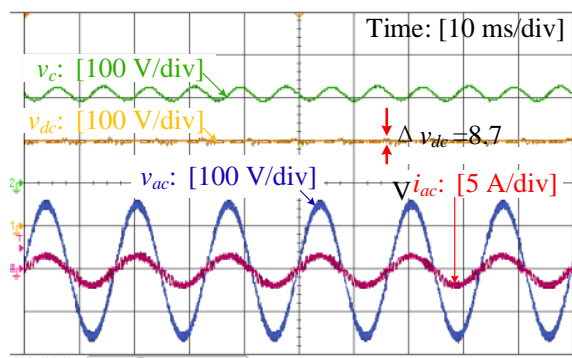

(c)

Fig. 13. Measured steady-state waveforms of the PFC rectifier at (a) $v_{d c}^{*}=100 \mathrm{~V}$, (b) $v_{d c}^{*}=150 \mathrm{~V}$ and (c) $v_{d c}^{*}=200 \mathrm{~V}$

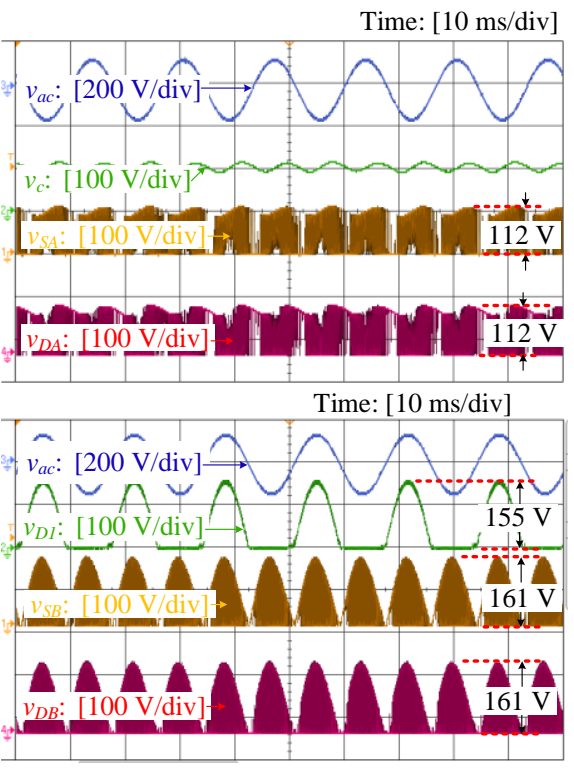

(a)

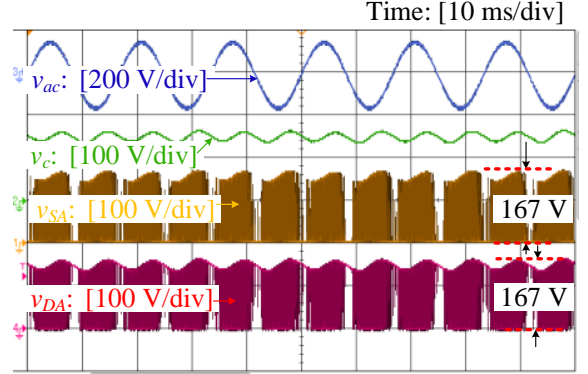

Time: $[10 \mathrm{~ms} / \mathrm{div}]$

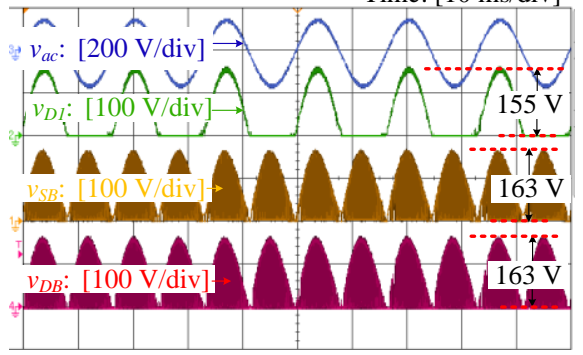

(b)

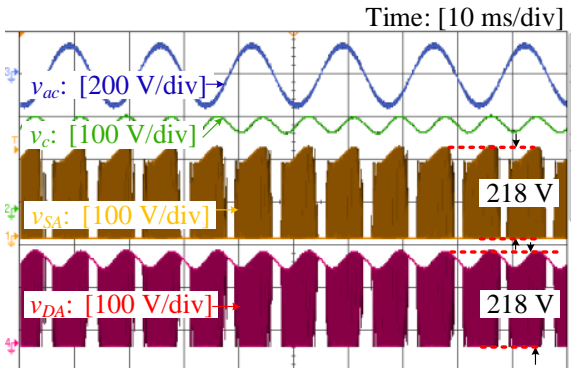

Time: $[10 \mathrm{~ms} / \mathrm{div}]$

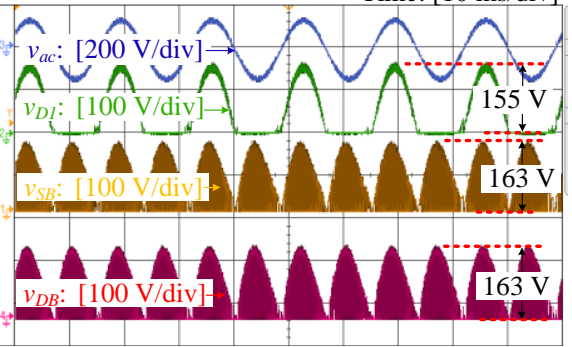

(c)

Fig. 14. Measured voltage waveforms of all switching devices at (a) $v_{d c}^{*}=100 \mathrm{~V}$, (b) $v_{d c}^{*}=150 \mathrm{~V}$ and (c) $v_{d c}^{*}=200 \mathrm{~V}$ 


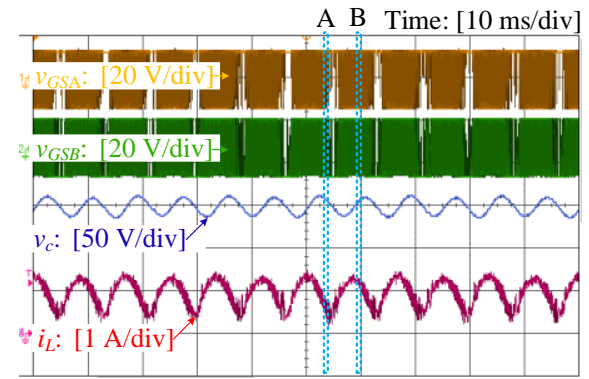

(a)

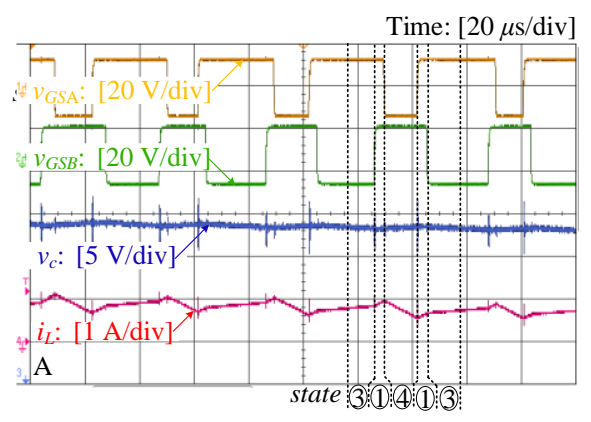

(b)

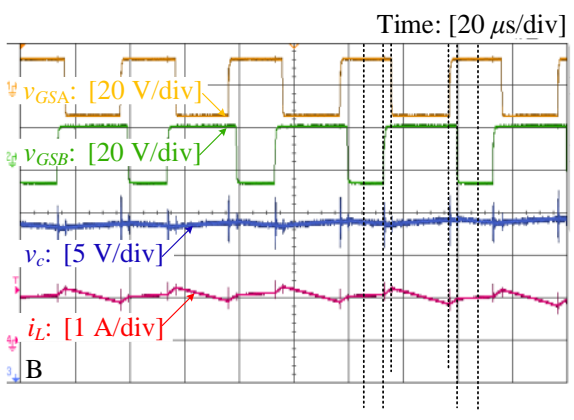

(c)

Fig. 15. (a) An overview of the switching waveforms of the inductor current and capacitor voltage against the gate signals, (b) zoom-in view at viewpoint A during the capacitor discharging phase and (c) at viewpoint B during the capacitor charging phase (viewpoint B).

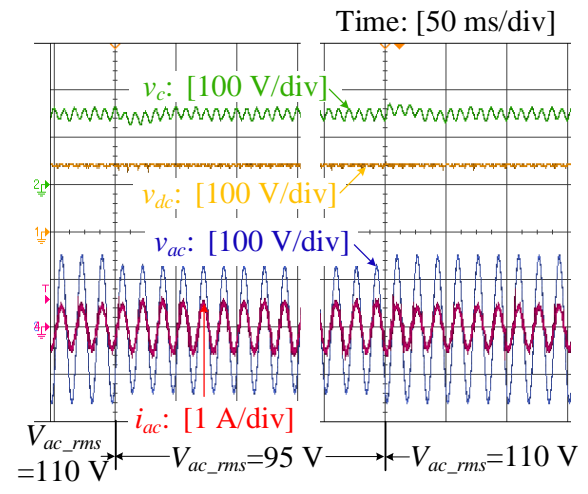

(a)

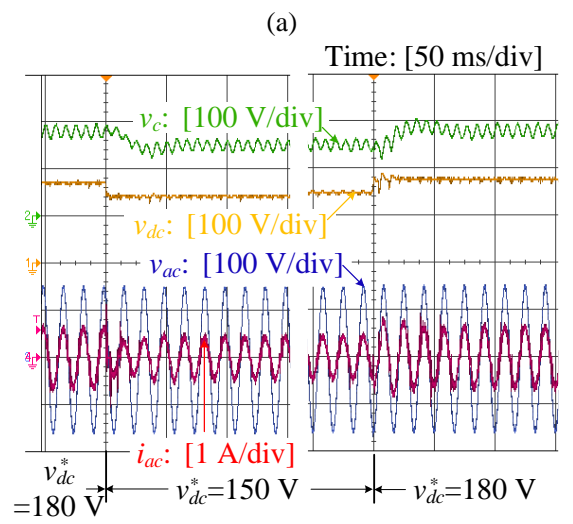

(b)

Fig. 16. Dynamic waveforms of the proposed rectifier in response to (a) a step change of the line voltage and (b) a step change of $v_{d c}^{*}$.

the bridge rectifier, exhibit almost identical voltage stresses closed to $V_{a c}$. In contrast, the voltage stresses for the active switches and diodes (excluding those in the bridge rectifier) in the conventional buck-boost converter and existing three-port PFC rectifier with PPB embedded switching must be at least doubled. The waveforms illustrated in Fig. 14 confirm the reduced voltage stresses of the proposed PFC rectifier.

Fig. 15 (a) shows an overview of the waveforms of the gate signals for $S_{A}$ and $S_{B}$, the inductor current $i_{L}$ and $v_{c}$. The zoom-in waveforms at viewpoint A (i.e., capacitor discharging phase) and B (i.e., capacitor charging phase) are shown in Fig. 15 (b) and (c), respectively. It can be observed that $d_{A}>d_{B}$ (or $d_{3}>d_{4}$ ) at viewpoint $\mathrm{A}$, meaning that $C_{b}$ is discharged for a longer duration than being charged, leading to a decreased $v_{c}$ over $T_{s}$. Conversely, $d_{A}<d_{B}$ (or $d_{3}<d_{4}$ ) at viewpoint B, meaning that $C_{b}$ is charged longer and $v_{c}$ is increasing. Fig. 15 also shows that the inductor current ripple $\Delta i_{L}$ is always lower than $0.6 \mathrm{~A}$, which agrees well with the designed values obtained in Section IV.

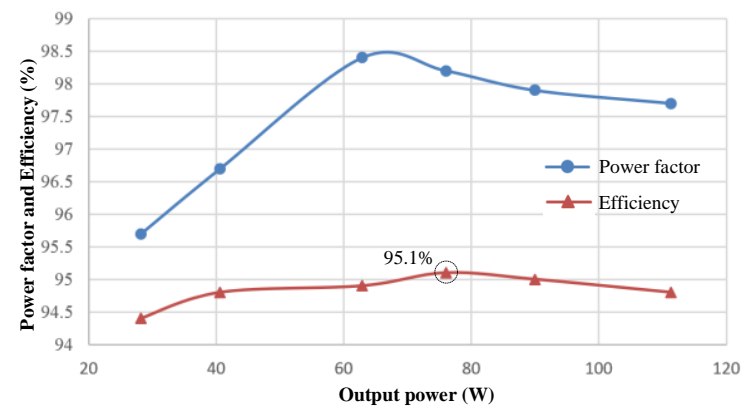

(a)

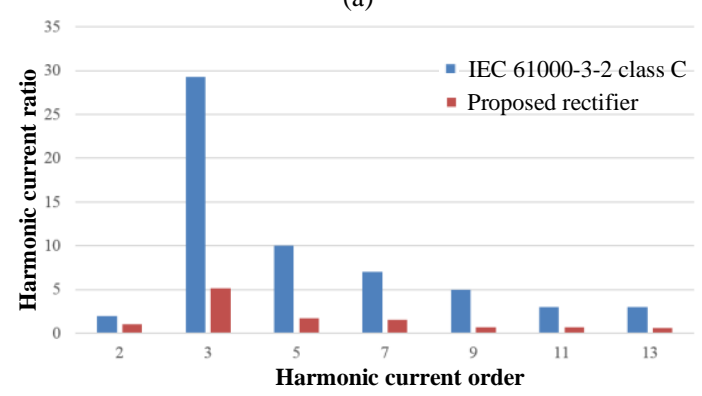

(b)

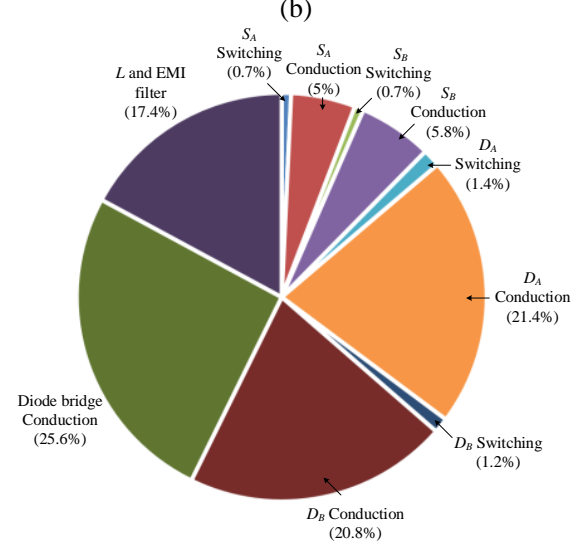

(c)

Fig. 17. (a) Measured power factor and efficiency of the proposed PFC rectifier versus the output power, (b) measured input current harmonics in comparison with IEC 61000-3-2 class C and (c) estimated loss breakdown.

The input voltage disturbance rejection capability and the reference tracking performance are also evaluated by stepping up/down the line voltage and the output voltage's reference, as illustrated in Fig. 16 (a) and (b) respectively. In Fig. 16 (a), 
despite large line voltage excursions, $v_{d c}$ is almost immune to the line voltage disturbances and the rectifier retains tight dc voltage regulation. The step change of the line voltage will produce a sudden change of the input power, leading to imbalanced power between the ac input and the dc output. Due to the robustness of the E-APD control strategy, the imbalanced power is automatically transferred to $C_{b}$, resulting in instant voltage variations in $v_{c}$ subsequent to the transient interval. In Fig. $16(\mathrm{~b}), v_{d c}$ tracks its reference in a first-order manner and reaches the steady state within $4 \mathrm{~ms}$ during the voltage step down test. The waveforms confirm the equivalent subsystem model in Fig. 6(b) and the designed time constant $\tau_{v}=0.8 \mathrm{~ms}$, and demonstrate fast reference tracking performance of the rectifier with E-APD control. Meanwhile, the averaged $v_{c}$ also changes accordingly to ensure proper circuit operation. The waveforms demonstrate fast reference tracking performance of the rectifier with E-APD control.

Fig. 17(a) illustrates the rectifier's power conversion efficiency over a load range from $30 \mathrm{~W}$ to $110 \mathrm{~W}$ (measured by changing the output voltage while fixing the load resistance at $350 \Omega$ ). The rectifier reaches a peak efficiency of $95.1 \%$ and the efficiency curve is shown to be fairly flat for a wide load range. The current spectrum of the line current is also recorded in Fig. 17(b) at full load (i.e., $110 \mathrm{~W}$ ). The results show that the rectifier meets IEC 61000-3-2 Class $\mathrm{C}$ limit whilst achieving a power factor of 0.977 and a total harmonics distortion of $5.8 \%$. Finally, an estimated power loss breakdown is illustrated in Fig. 17 (c) at full load (i.e., $110 \mathrm{~W}$ ). The results show that the major losses of the rectifier are the conduction losses of the diodes $(67.8 \%)$.

\section{CONCLUSIONS}

In this paper, a single-phase three-level flying-capacitor PFC rectifier without electrolytic capacitor is proposed. By taking advantage of its inherent PPB embedded switching capabilities, the rectifier features only two active switches, one inductor, and two small capacitors. Additionally, with a three-level configuration, the voltage stresses for power devices are effectively reduced. Moreover, through quantitative analysis, it is shown that the minimum inductance requirement of the rectifier is closely related to the patterns of the modulation carriers. Out-of-phase carries are employed, enabling more than $60 \%$ inductance reduction as compared to the case when in-phase carriers are used. Experiments on a 110-W hardware prototype demonstrated the feasibilities of the proposed rectifier.

\section{REFERENCES}

M. Rico-secades, A. J. Calleja, J. Ribas, E. L. Corominas, J. M. Alonso, J. Cardesín, and J. García-garcía, "Evaluation of a low-cost permanent emergency lighting system based on high-efficiency LEDs,” IEEE Trans. Ind. Appl., vol. 41, no. 5, pp. 1386-1390, Sep. 2005.

[2] P. S. Almeida, D. Camponogara, M. A. D. Costa, H. Braga, and J. M. Alonso, "Matching LED and driver life spans: a review of different techniques," IEEE Ind. Electron. Mag., vol. 9, no. 2, pp. 36-47, Jun.
2015.

[3] Y. Wang, J. M. Alonso, and X. Ruan, "A review of LED drivers and related technologies," IEEE Trans. Ind. Electron., vol. 64, no. 7, pp. 5754-5765, Jul. 2017.

[4] Y. Y.-C. Li and C.-L. C. Chen, "A Novel Single-Stage High-Power-Factor AC-to-DC LED Driving Circuit With Leakage Inductance Energy Recycling," IEEE Trans. Ind. Electron., vol. 59, no. 2, pp. 793-802, Feb. 2012.

[5] J. M. Alonso, J. Viña, D. G. Vaquero, G. Martínez, and R. Osorio, "Analysis and design of the integrated double Buck - Boost converter as a high-power-factor driver for power-LED lamps," IEEE Trans. Ind. Electron., vol. 59, no. 4, pp. 1689-1697, Apr. 2012.

[6] S. Li, S. C. Tan, C. K. Lee, E. Waffenschmidt, S. Y. R. Hui, and C. K. Tse, "A survey, classification, and critical review of light-emitting diode drivers," IEEE Trans. Power Electron., vol. 31, no. 2, pp. 1503-1516, Feb. 2016.

[7] M. Chen, S. Chakraborty, and D. J. Perreault, "Multitrack power factor correction architecture," IEEE Trans. Power Electron., 2018.

[8] Z. Liu, F. C. Lee, Q. Li, and Y. Yang, "Design of GaN-based MHz totem-pole PFC rectifier," IEEE J. Emerg. Sel. Top. Power Electron., vol. 4, no. 3, pp. 799-807, Sep. 2016.

[9] L. Zhang, R. Born, X. Zhao, and J. S. Lai, "A high efficiency inverter design for Google little box challenge," WiPDA 2015 - 3rd IEEE Work. Wide Bandgap Power Devices Appl., pp. 319-322, 2015.

[10] S. B. Kjaer, J. K. Pedersen, and F. Blaabjerg, "A review of single-phase grid-connected inverters for photovoltaic modules," IEEE Trans. Ind. Appl., vol. 41, no. 5, pp. 1292-1306, Sep. 2005.

[11] H. Hu, S. Harb, N. Kutkut, I. Batarseh, and Z. J. Shen, "A review of power decoupling techniques for microinverters with three different decoupling capacitor locations in PV systems," IEEE Trans. Power Electron., vol. 28, no. 6, pp. 2711-2726, Jun. 2013.

[12] M. A. Vitorino, L. F. S. Alves, R. Wang, and M. B. De Rossiter Correa, "Low-frequency power decoupling in single-phase applications: a comprehensive overview," IEEE Trans. Power Electron., vol. 32, no. 4, pp. 2892-2912, Apr. 2017.

[13] Q. Li and P. Wolfs, "A review of the single phase photovoltaic module integrated converter topologies with three different DC link configurations," IEEE Trans. Power Electron., vol. 23, no. 3, pp. 1320-1333, May 2008.

[14] H. Watanabe, T. Sakuraba, K. Furukawa, K. Kusaka, and J. Itoh, "Development of DC to single-phase AC voltage source inverter with active power decoupling based on flying-capacitor DC/DC converter," IEEE Trans. Power Electron., vol. 33, no. 6, pp. 4992-5004, Jun. 2018.

[15] R. Wang, F. Wang, D. Boroyevich, R. Burgos, R. Lai, P. Ning, and K. Rajashekara, "A high power density single-phase PWM rectifier with active ripple energy storage," IEEE Trans. Power Electron., vol. 26, no. 5, pp. 1430-1443, May 2011.

[16] S. Wang, X. Ruan, K. Yao, and Z. Ye, "A flicker-free electrolytic capacitor-less ac-dc LED driver," in 2011 IEEE Energy Conversion Congress and Exposition, 2011, pp. 2318-2325.

[17] W. Qi, H. Wang, X. Tan, G. Wang, and K. D. T. Ngo, "A novel active power decoupling single-phase PWM rectifier topology," in Conference Proceedings - IEEE Applied Power Electronics Conference and Exposition - APEC, 2014, pp. 89-95.

[18] S. Li, W. Qi, S. C. Tan, and S. Y. R. Hui, "Integration of an active filter and a single-phase AC/DC converter with reduced capacitance requirement and component count," IEEE Trans. Power Electron., vol. 31, no. 6, pp. 4121-4137, Jun. 2016.

[19] Y. Tang and F. Blaabjerg, "A component-minimized single-phase active power decoupling circuit with reduced current stress to semiconductor switches," IEEE Trans. Power Electron., vol. 30, no. 6, pp. 2905-2910, Jun. 2015.

[20] Q. C. Zhong, W. L. Ming, W. Sheng, and Y. Zhao, "Beijing converters: bridge converters with a capacitor added to reduce leakage currents, DC-bus voltage ripples, and total capacitance required," IEEE Trans. Ind. Electron., vol. 64, no. 1, pp. 325-335, Jan. 2017.

[21] S. Li, G.-R. Zhu, S.-C. Tan, and S. Y. R. Hui, "Direct ac/de rectifier with mitigated low-frequency ripple through inductor-current waveform control," IEEE Trans. Power Electron., vol. 30, no. 8, pp. 4336-4348, Aug. 2015. 
[22] Y. Ohnuma and J. I. Itoh, "A novel single-phase buck PFC AC-DC converter with power decoupling capability using an active buffer," IEEE Trans. Ind. Appl., vol. 50, no. 3, pp. 1905-1914, May 2014.

[23] S. Li, W. Qi, S. C. Tan, and S. Y. Ron Hui, "A single-stage two-switch PFC rectifier with wide output voltage range and automatic AC ripple power decoupling," IEEE Trans. Power Electron., vol. 32, no. 9, pp. 6971-6982, Sep. 2017.

[24] Y. Liu, Y. Sun, M. Su, and F. Liu, "Control method for the Sheppard - Taylor PFC rectifier to reduce capacitance requirements," IEEE Trans. Power Electron., vol. 33, no. 3, pp. 2714-2722, Mar. 2018.

[25] Y. Liu, Y. Sun, and M. Su, "A control method for bridgeless Cuk/Sepic PFC rectifier to achieve power decoupling," IEEE Trans. Ind. Electron., vol. 64, no. 9, pp. 7272-7276, Sep. 2017.

[26] Y. Lei, C. Barth, S. Qin, W.-C. Liu, I. Moon, A. Stillwell, D. Chou, T. Foulkes, Z. Ye, Z. Liao, and R. C. N. Pilawa-Podgurski, "A 2-kW single-phase seven-level flying capacitor multilevel inverter with an active energy buffer," IEEE Trans. Power Electron., vol. 32, no. 11, pp. 8570-8581, Nov. 2017.

[27] P. T. Krein, R. S. Balog, and M. Mirjafari, "Minimum energy and capacitance requirements for single-phase inverters and rectifiers using a ripple port," IEEE Trans. Power Electron., vol. 27, no. 11, pp. 4690-4698, Nov. 2012.

[28] T. A. Meynard, M. Fadel, and N. Aouda, "Modeling of multilevel converters," IEEE Trans. Ind. Electron., vol. 44, no. 3, pp. 356-364, Jun. 1997.

[29] S. Li, W. Qi, S.-C. Tan, and S. Y. R. Hui, "Enhanced Automatic-Power-Decoupling Control Method for Single-Phase AC-to-DC Converters," IEEE Trans. Power Electron., 2018.

[30] H. W. Yuan, S. Li, W. Qi, S. C. Tan, and S. Y. R. Hui, "On Nonlinear Control of Single-Phase Converters with Active Power Decoupling Function," IEEE Trans. Power Electron., p. pp, 2018.

Wenlong Qi (S'14) received the B.E.

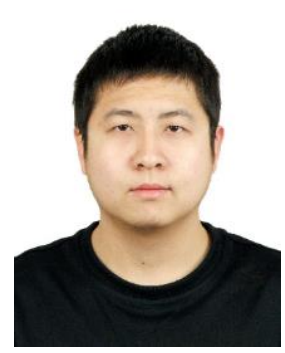
and M.E. degrees from the Shandong University, Jinan, China, in 2011 and 2014, respectively. $\mathrm{He}$ is currently working toward the Ph.D. degree in the Department of Electrical and Electronic Engineering, The University of Hong Kong, Hong Kong.

$\mathrm{He}$ has published more than 10 transaction papers and conference papers. He also holds two Chinese patents. His current research areas include nonlinear control technique and single-phase inverters and rectifiers.

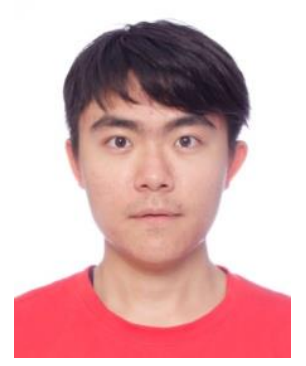

Sinan Li (M'14) received the B.S. degree in electrical engineering from Harbin Institute of Technology, China, in 2009, and the Ph.D. degree in electrical and electronic engineering from The University of Hong Kong, Hong Kong, China, in 2014.

$\mathrm{He}$ is currently a Postdoctoral Research Fellow with the Department of Electrical and Electronic Engineering, The University of Hong Kong. He has published more than 40 transaction papers and conference papers. He also holds five U.S. patents, and three of these patents have been adopted by industry. His current research areas include power electronics and control, wireless power transfer, renewable energy, and smart grids. Dr. Li is a founding member of IEEE-Eta Kappa $\mathrm{Nu}(\mathrm{HKN})$ at HKU.

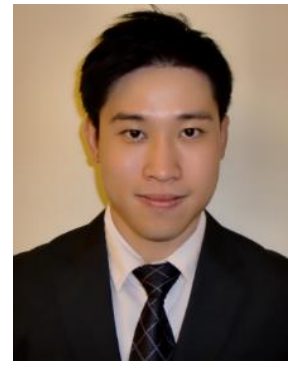

Siew-Chong Tan (S'00-M'06SM'11) received the B.Eng. (Hons.) and M.Eng. degrees in electrical and computer engineering from the National University of Singapore, Singapore, in 2000 and 2002, respectively, and the Ph.D. degree in electronic and information engineering from the Hong Kong Polytechnic University, Hong Kong, in 2005.

From October 2005 to May 2012, he worked as Research Associate, Postdoctoral Fellow, Lecturer, and Assistant Professor in Department of Electronic and Information Engineering, Hong Kong Polytechnic University, Hong Kong. From January to October 2011, he was Senior Scientist in Agency for Science, Technology and Research (A*Star), Singapore. He is currently a Professor in Department of Electrical and Electronic Engineering, The University of Hong Kong, Hong Kong.

Dr. Tan serves extensively as a reviewer for various IEEE/IET transactions and journals on power, electronics, circuits, and control engineering. He is a coauthor of the book Sliding Mode Control of Switching Power Converters: Techniques and Implementation.

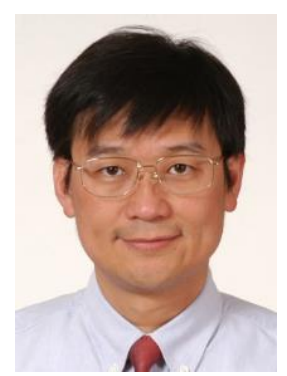

S. Y. (Ron) Hui (M'87-SM'94-F'03) received the B.Sc.(Hons.) Eng. degree in electrical and electronic engineering from the University of Birmingham, Birmingham, U.K., in 1984, and the D.I.C. and Ph.D. degrees from Imperial College London, London, U.K., in 1987. Since July 2010, he has been concurrently a part-time Chair Professor of Power Electronics at Imperial College London and Philip Wong Wilson Wong Professor at The University of Hong Kong, Pokfulam, Hong Kong. He has published more than 260 refereed journal publications and book chapters, and more than 60 of his patents have been adopted by industry. Dr. Hui is an Associate Editor of the IEEE TRANSACTIONS ON POWER ELECTRONICS and IEEE TRANSACTIONS ON INDUSTRIAL ELECTRONICS. He is the recipient of the 2010 IEEE Rodulf Chope R\&D Award from the IEEE Industrial Electronics Society, 2010 IET Crompton Medal, and 2015 IEEE William E. Newell Power Electronics Award. He is a Fellow of the Australian Academy of Technological Sciences and Engineering and also the Royal Academy of Engineering (U.K.). 